\title{
ARTICLE
}

\section{The Larnaca Declaration on Learning Design}

\author{
James Dalziel*, Grainne Conole†, Sandra Wills ${ }^{\ddagger}$, Simon Walker ${ }^{\S}$, Sue Bennett"l, \\ Eva Dobozy", Leanne Cameron**, Emil Badilescu-Buga ${ }^{\dagger \dagger}$ and Matt Bower ${ }^{\dagger \dagger}$
}

\begin{abstract}
The Larnaca Declaration on Learning Design arose from a 2012 meeting of experts in Larnaca, Cyprus who sought to provide a new theoretical foundation for the field of Learning Design, based on a synthesis of research and practice in the field to date. It begins by acknowledging the vast benefits that would arise from wider sharing of effective teaching practices, and it uses an analogy from the history of music notation to identify the need for a representational framework for describing teaching and learning ideas. It provides a range of examples of learning designs and different representational systems to illustrate the need for a "Learning Design Framework" (LD-F). It then acknowledges the wider educational context and its impact on design decisions by educators, and provides a "Learning Design Conceptual Map" (LD-CM) to identify contextual components and their interactions in design decisions. It concludes by discussing the philosophical and practical challenges of identifying and sharing effective teaching and learning ideas under the heading "Learning Design Practice" (LD-P).
\end{abstract}

Keyword: learning design

\section{Introduction}

Education faces many challenges in the changing modern world. Learners are changing in their approaches to education - they use digital technologies, they multi-task, they collaborate and they are becoming less patient with teacher-centric styles of education.

Educators ${ }^{1}$ face many changes - such as expectations of adopting innovative teaching approaches, alignment of teaching to external standards, growing requirements for professional development and difficulties in balancing a complex range of demands from different stakeholders.

Government and educational institutions also face many changes, such as the rise of the knowledge economy and the

\footnotetext{
* LAMS Foundation, AU

jamesrdalziel@gmail.com

+ University of Bath Spa, GB

g.conole@bathspa.ac.uk

* Charles Sturt University, AU

swills@csu.edu.au

§ University of Greenwich, GB

S.Walker@greenwich.ac.uk

" University of Wollongong, AU

sbennett@uow.edu.au

" Curtin University, AU

Eva.Dobozy@curtin.edu.au

${ }^{* *}$ Australian Catholic University, AU

I.cameron@acu.au

${ }^{\dagger+}$ Macquarie University, AU

emil.badilescu-buga@mq.edu.au, matt.bower@mq.edu.au
}

need for different kinds of graduates, a shift from knowledge scarcity to abundance, and the impact of technology especially the internet via open sharing of educational resources and massive open online courses (MOOCs).

In the context of these changes, effective teaching and learning in the classroom ${ }^{2}$ (and beyond) remains central. How can educators become more effective in their preparation and facilitation of teaching and learning activities? How can educators be exposed to new teaching ideas that take them beyond their traditional approaches? How can technology assist educators without undermining them? How can learners be better prepared for the world that awaits them?

This paper describes how the new field of Learning Design contributes to the central challenge of improving teaching and learning. Learning Design can assist educators to describe effective teaching ideas so that they can be shared with, and adapted by, other educators. While the field has primarily focussed on higher education and $\mathrm{K}-12$ schools to date, it also has implications for vocational and professional training. This paper describes how ongoing work to develop a descriptive language for teaching and learning activities (often including the use of technology) is changing the way educators think about planning and facilitating educational activities. The ultimate goal of Learning Design is to convey great teaching ideas among educators in order to improve student learning.

The paper begins with this Introduction, followed by an analogy from music to provide a context for Part 1 , which considers the possibility of educational notation. Part 2 describes how this possibility is being realised in the field 
of Learning Design, illustrated with an example based on a Role Play. Part 3 considers current definitional challenges in Learning Design and its provocative aspiration towards pedagogical neutrality. Part 4 provides a wider conceptual map of education for exploring the place of Learning Design, including more examples of current Learning Design approaches, and how the map can be used to analyse pedagogical theories. Part 5 returns to the relationship between Learning Design and pedagogical theories, and the central question of effective teaching and learning approaches. The Conclusion offers a new synthesis of the ideas discussed in this paper as a foundation for the future of Learning Design, and the Epilogue returns to the music analogy to reflect on the future prospects of this synthesis.

While the concepts discussed in this paper have potentially far-reaching implications for many aspects of education, this paper is written primarily for those with an interest in Learning Design and in pedagogical theories. Future work based on this paper will explore these ideas in different ways for other audiences, such as policy makers and typical educators.

\section{An analogy from music}

In the history of music there was a time long ago when some people argued it was impossible to write down music - music was too special, too ethereal - to ever be reduced to written form.

However, over many years the Western music tradition slowly developed a notational system for describing and sharing musical ideas. This standard format allowed great musical ideas to be shared from one musician to another without a need for personal contact.

As a result, a musician living hundreds of years later, in a very different context, can still understand the musical ideas of a composer long ago, and with appropriate skills, can reproduce those musical ideas.

Music notation does not capture everything about musical ideas - there remains a significant role for performers to bring their own interpretations to music. But musical notation contains enough information to convey musical ideas from one person to another over time and space.

Music notation does not guarantee beautiful music indeed, mediocre music can be written down just as precisely as beautiful music. Music notation allows for many different styles of music to be described using a single notational framework. And while the Western notational framework is sufficiently broad to describe many types of music, it contains limitations that make some kinds of music (e.g., quartertone singing) difficult to describe within the standard format.

The purpose of creating musical notation was not simply the abstract concept of music representation; rather, it was a vehicle for conveying great musical ideas to others. This sharing helps other musicians to learn the crafts of performance and composition, as well as enriching countless lives who listen to music that they would never have heard if it had not been written down many years ago.

\section{Part 1: Educational Notation?}

Can we apply the lesson of music notation to education? Could we develop a way to describe the activities of educators and learners in classrooms (and online) so that great teaching ideas could be conveyed from one educator to another? Can we help to make implicit, private teaching ideas into explicit, shared ideas?

In this paper, we focus on the particular requirements of formal education where an educator plays at least some role in structuring learning activities for learners. Self-study, and learning in groups where there is no educator or educator-like role, is outside our current scope. This should not be taken to mean that we focus only on "teacher-centric" education - far from it - but it is simply to note that our scope is the potential for educators to learn about good teaching ideas from other educators. These ideas may call for an active role for the educator ${ }^{3}$ in directing activities, or the educator's role may be to facilitate learners as active managers of their learning.

In one sense, we have made progress already. The "content" dimension of education is captured in books, websites, recorded lectures, videos and other resources. But content transmission is not the only dimension of education - otherwise educational institutions would need only libraries, rather than libraries and classrooms.

Describing teaching and learning activities - what educators and learners actually do in classrooms and online is less developed. In many school contexts there is a tradition of written lesson plans, and individual educators in universities and vocational training may write down activity plans for tutorials and practical workshops. But there is no generally agreed notational system for educational activities that has the expressiveness or widespread adoption of music notation.

If one stops to reflect for a moment, this is a surprising situation. Many educators could benefit from learning about the great teaching ideas of their colleagues, yet our ability to convey a great teaching idea from one educator to another is hampered by our lack of a common language for what we do in classrooms and online. We struggle to describe even something as simple as how different activities are conducted over time in a classroom (e.g., lecturing, small group debate, whole class discussion, individual reading, practical tasks, etc.) or its online equivalents.

Many very bright people have been educators, so the lack of a descriptive framework for education could be interpreted as follows: it is a very hard problem - if it wasn't, some bright person would have solved it already.

By comparison with music notation, a descriptive framework for teaching and learning activities would not describe everything that occurs - rather, it would seek to convey enough information so that one educator could benefit from the great ideas of another educator. These educational ideas could be of many different kinds, based on different underlying pedagogical theories, in a manner similar to different styles of music.

Just as with beautiful or mediocre music, an educational notation system would not guarantee that the ideas written down would be educationally effective - rather, it is 
simply a way of conveying an educational idea using a common framework. And as with the problem of representing quartertone singing in the Western music notation, any system of educational notation will have weaknesses in describing some types of education, even where it is strong at describing others. Given the hard nature of the problem and the immaturity of this field, it is likely that early educational notation systems will have many weaknesses and few strengths, but in the same way that music notation has improved over time, the same may occur for educational notation.

One important difference between music performances and teaching is that it is typical for musicians to faithfully reproduce the written musical idea. In education, however, there is an important role for educators to be able to adapt their teaching in response to the unique needs of their learners. This adaptation could take the form of reflecting on a great teaching idea from a colleague, then reworking the idea for a future class based on the educator's insights into his/her learners' needs. Another kind of adaptation is where an educator decides to change his/her approach in the middle of a class - perhaps because the original plan is not working out as expected, or interesting new ideas have arisen in class that are worth pursuing.

Interestingly, the analogy with music does not break down completely at this point. There are traditions of improvisation in music (e.g., Jazz) that take into account the immediate evolving music experience (often due to the musical interactions between performers). But even improvisation often uses some predetermined basic musical structures, such as the chord progressions in the twelve-bar blues.

Another point of comparison with music is whether the notation is for use by the creator of the musical experience, or for use by others. If a musician composes a piece of music for their own performance, they may not write it down using musical notation (or they may only write down a brief summary, such as guitar chords), as the musician remembers the details for performance. But when the musician wishes to convey the musical idea to another musician, musical notation becomes important. As many educators "compose" their teaching ideas for their own use, the need for notation may not be pressing in these cases; and yet when educators wish to convey a great teaching idea to other educators, they lack an agreed format for communication. An agreed notation format would also assist with other facets of education, such as documentation, quality assurance and enhancement of teaching and learning activities.

There are two compelling reasons for developing a system of educational notation. First, teaching is sometimes called the loneliest profession (Hooker, 1949) as individual educators often have little exposure to each other's teaching. In many ways, the craft of teaching is still at a relatively amateur stage, and lacks the professionalisation that would come from a richer language for describing the essence of teaching and learning activities. While there are examples of team teaching and teacher observation in some contexts, there is much more that could be done to share good teaching practice, and a common notational format could assist this sharing.

Second, modern society and business expect more of graduates than just content knowledge. Skills such as problem solving, teamwork, effective communication, creativity, intercultural understanding, critical thinking and others are required for success in the "knowledge economy". These skills have been called graduate attributes, soft skills, generic skills or $21^{\text {st }}$ Century skills. These skills are difficult to learn in the abstract - instead, they need to be learned by working with content knowledge. Given this, transforming education for the $21^{\text {st }}$ century means redesigning the core teaching and learning activities used with content knowledge, rather than simply adding extra courses on these broader skills, and leaving content teaching practices untouched.

As many educators find it challenging to combine content knowledge and the development of these broader skills in day-to-day teaching and learning activities, there is a need for professional development about innovative teaching structures that address this challenge (such as Problem-Based Learning, Role Plays, WebQuests and similar teaching strategies). While there are many aspects to this professional development, there would be significant benefits from a common language for describing great teaching ideas, just as an important part of learning a musical instrument is understanding and playing great music.

While the primary focus of this paper is the implications of educational notation for pedagogical theory and practice, it should be noted that there are also productivity implications. If educators can easily re-use and adapt the good ideas of their colleagues, then the preparation time for teaching may decrease (consider the many educators across the world re-inventing similar teaching plans each day). That is, successful sharing of good teaching ideas can lead not only to more effective teaching, but also to more efficient preparation for teaching. These productivity benefits may lead to increased cost effectiveness in some contexts, but for many educators, the benefit is more likely to be increased "time effectiveness" - that is, time savings in one area of teaching (e.g., preparation) allow for more time on other areas (e.g., more individual feedback to learners).

In summary, we take inspiration from the history and uses of music notation to try to imagine a descriptive framework for teaching and learning activities that is broad enough to describe many different pedagogical approaches. A framework of this kind could help to propagate great teaching ideas in order to enhance the effectiveness of educators, leading to richer learning experiences for learners. There are other examples of descriptive frameworks that could be considered - patterns and plans in architecture, recipes, the Unified Modelling Language (UML) in software development, dance notation, etc. We leave it to other experts to draw out lessons for education from other descriptive frameworks - in this paper we use music notation as an extended analogy for imagining education notation. In the next section we describe work 
on educational notation in the field of Learning Design, followed by a new conceptual map for Learning Design and the broader education landscape.

\section{Part 2: Learning Design}

The new field of Learning Design seeks to develop a descriptive framework for teaching and learning activities ("educational notation"), and to explore how this framework can assist educators to share and adopt great teaching ideas.

While there has been work on standardised lesson plans formats and re-usable educational software over several decades, the field of Learning Design has its origins in four somewhat distinct projects around the turn of the millennium. While the concept of a descriptive framework is applicable to all kinds of education - including online education and face-to-face activities - early work in this field was heavily focussed on technological implementation.

The first foundational project was the development of the Educational Modelling Language (EML) by Rob Koper and colleagues at the Open University of the Netherlands (Koper, 2001), which subsequently was adopted as the basis for the IMS Learning Design technical specification in 2003 (IMS GLC, 2003). The second was a diverse body of research on technology in higher education in the UK, particularly the SoURCE project (e.g., Laurillard \& McAndrew, 2002) and the work of Diana Laurillard, Grainne Conole, Helen Beetham and others. The third project was the Australian Universities Teaching Council (AUTC) Learning Design project based at Wollongong University, led by Ron Oliver, Barry Harper, John Hedberg and Sandra Wills (this project had explicit links to the second project). The fourth project was the "Learning Activity Management System" (LAMS) project led by James Dalziel at Macquarie University, Australia (Dalziel, 2003).

All four projects had a similar underlying vision of improvement of teaching and learning through the development and implementation of a descriptive framework. For EML and LAMS, this led to a technical language for describing and sharing sequences of online learning activities (IMS LD and LAMS LD respectively) and software systems for teacher authoring and learner implementation of activities (ReLoad/CopperCore/SLeD and LAMS). To continue the music notation analogy, the technical language for implementation by an educational software system could be compared to using a piano roll with a mechanical player piano (or MIDI in modern electronic instruments). These projects also developed online communities for sharing of sequences (Unfold and the LAMS Community).

The SoURCE and AUTC Learning Design projects both developed exemplars of software systems, but not to the same level of implementation as the other two projects. However, these two projects included a strong focus on describing and sharing pedagogically effective sequences of activities - particularly the third project through an online library of examples (see www.learningdesigns.uow. edu.au).

From these origins, a wide range of related projects, conferences and research activities arose, with a growing breadth of interests that incorporated not only technological issues but also support for educators in adopting innovative teaching methods - see Table $\mathbf{1}$ for a sample of areas and early examples.

As at 2012, the body of work on Learning Design is beyond easy summary within the constraints of this article, so as an aid to those who are interested in understanding the field to date, we have developed a timeline of Learning Design-related initiatives/projects, communities, software tools, conferences and other key events and publications - this is provided in Figure 1, with more detailed information about the elements of this figure (as well as the projects noted in Table 1) available at http://learningdesigntimeline.wordpress.com/

\section{Part 2.1: Example of a learning design}

Given the range of projects and software systems noted above, there are many ways to describe a particular learning design, but for the sake of clarity we provide one example below to provide a concrete illustration.
Areas of Application of Learning Design

Foundation projects

Advice to educators on adopting new teaching ideas

Description and sharing of particular teaching methods

Adaptation of existing technologies to implement Learning Design

Technology to support reflection on the design of teaching and learning

Communities and/or repositories for Learning Design

Major Learning Design-related funding programs

Learning Design Conferences

\section{Early Examples}

EML/IMS Learning Design, SoURCE, AUTC Learning Design, LAMS

DialogPlus, LearningMapR

EnRoLE (Role Plays), COLLAGE (e.g., Jigsaws)

MOT+, Grail (adaptation of .LRN)

London Planner/Learning Designer, Phoebe, LAMS Activity Planner

Unfold, LAMS Community, Cloudworks

JISC Design for Learning, EU TenCompetence

LAMS Conferences, CETIS DesignBash,

TenCompetence Conferences

Table 1: A sample of different areas of the growing field of Learning Design including early examples. 


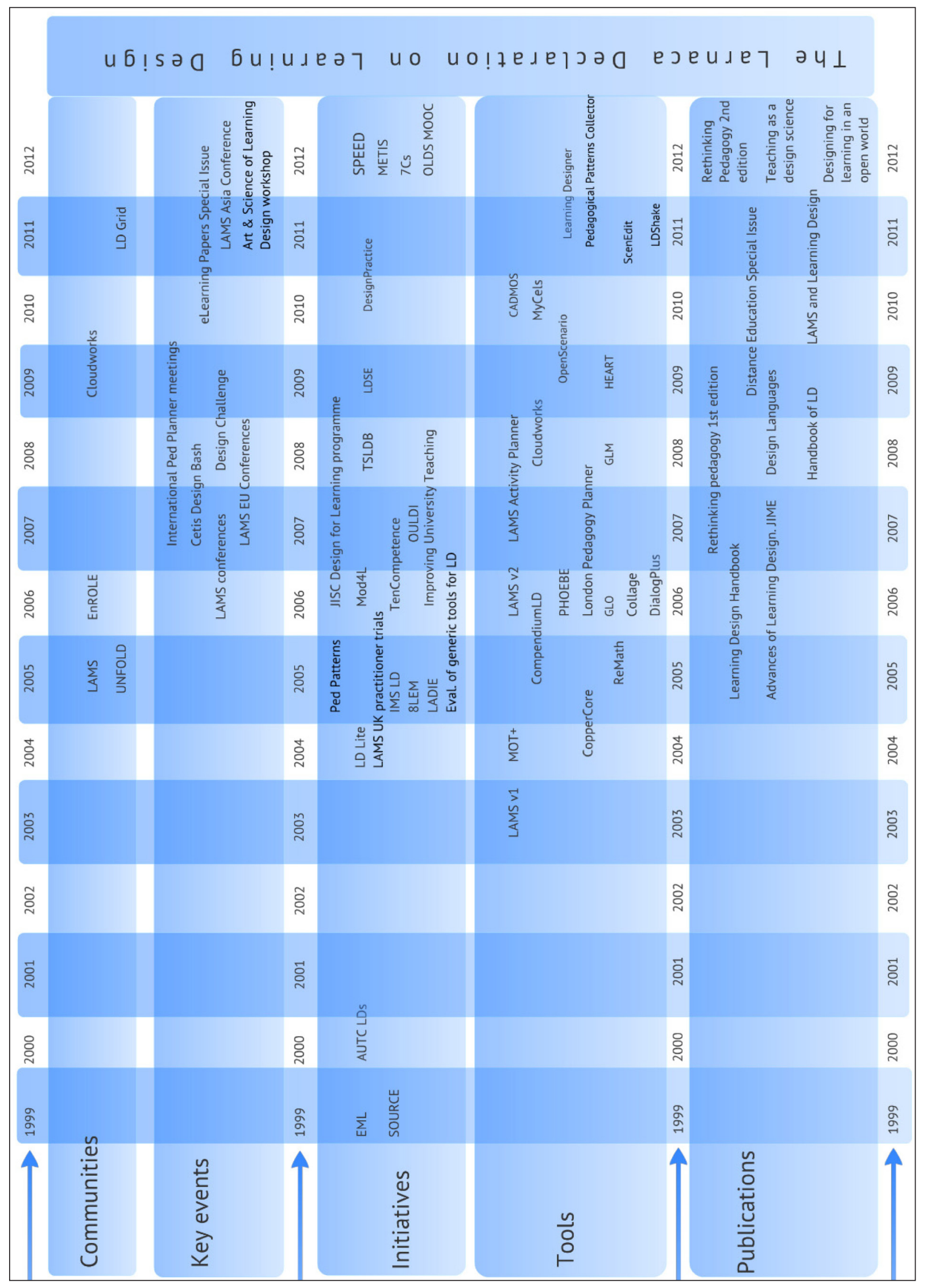


An innovative, potentially effective teaching strategy is a "Role Play". In this strategy, learners are presented with a scenario in which they take on different roles and then "play out" the scenario based on their allocated roles, with facilitation by the educator as required. Role Plays have been prominent in many discussions of Learning Design, such as the Versailles Use Case in IMS Learning Design, the six Role Plays in the AUTC Learning Design project, the EnRoLE Project, the Role Play Pattern in the COLLAGE project, and others.

There are some narrow types of Role Plays used in specific disciplines, such as practicing conversation in language learning or practicing a business interaction (e.g., a call centre conversation). However, the more general kind of Role Play typically involves a complex scenario in which learners take on a role that is unfamiliar to their normal life, and hence they need to try to see the world from someone else's perspective. This "walking in the shoes of another" is the most powerful quality of Role Plays as a teaching strategy as it can assist development of selfreflective/meta-cognitive skills. While Role Plays may not be suitable in some disciplines (e.g., mathematics), they can be used in many disciplines where understanding of different perspectives is relevant.

Putting aside the rationale for choosing a Role Play as a teaching strategy (the "why"), a Learning Design approach would seek to describe the sequence of teaching and learning activities that make up the Role Play experience (the "what and how"). The goal of this description is to provide educators with enough information that they could replicate this teaching and learning experience. In broad terms, a Role Play typically involves four main "phases":

1. A description of the scenario and the roles within it.

2. Allocation of learners to roles, then learners prepare for the Role Play proper by seeking to better understand their allocated role. As multiple learners are often allocated to each role, this can involve each role group discussing their ideas about their role (privately).

3. The "Role Play proper", in which all learners come together to play out their roles in the given scenario.

4. After conclusion of the Role Play proper, learners debrief on the experience of playing their role and reflect on what they have learned from "walking in the shoes of another".

To give a concrete example of a Role Play in a school-based teacher training course:

1. The scenario is about the adoption of interactive whiteboards in a typical school. There are four roles in the imaginary school (teachers in favour of interactive whiteboards, teachers with concerns about interactive whiteboards, school management and school students).

2. Each participant in the Role Play is allocated to a role, and then each role group gets together privately to discuss their role and their ideas about the scenario, and how they could respond to the other role groups. They may also conduct research on the scenario as it relates to their role and discuss this within their role group.

3. All role groups come together to discuss/debate the merits of adopting interactive whiteboards in the imaginary school. Participants in each role group make their case, and interact with other roles as they play their own role while debating the merits of adopting interactive whiteboards.

4. After concluding the Role Play, the trainee teachers debrief as they "return to being themselves" and reflect on the discussion in the Role Play proper, and on how their personal views compare to those expressed in their role.

There are still many practical issues to be considered in implementing this Role Play - such as the timing of each activity, any particular resources required within each phase, the readiness of the learners to participate in this Role Play in the expected way, the role of the educator as facilitator/umpire, etc. An experienced educator may be able to make judgements on these issues from existing experience without requiring detailed descriptive information, whereas a novice educator may need more comprehensive advice on these details prior to implementation (just as an experienced musician can read music notation and infer how to interpret the music for a performance, but a novice musician may need more advice on interpretation).

One way of implementing this Role Play is in an online environment where discussion is conducted through an online forum (or similar tool). Figure $\mathbf{2}$ provides an example of the interactive whiteboards Role Play as represented in the Authoring environment of the LAMS Learning Design system. In this example, the first phase corresponds to a number of instruction pages about the scenario, then learners split into role groups, and within the "branching" area learners conduct a number of reflection and discussion activities about their role (activity detail not shown). Later, the educator/facilitator opens the "stop" gate so that learners enter the Role Play proper in a discussion forum. After concluding the Role Play proper, the educator/facilitator opens the second "stop" gate to provide learners with a series of reflective activities for debriefing.

For those familiar with LAMS, the colour and icons of each activity (i.e., each box) provides information about the type of online tool being used at each stage (e.g., information page, discussion forum, voting tool, shared question and answer). This means that the visualisation provided in Figure $\mathbf{2}$ conveys information about the structure and sequence of this learning design and the nature of individual activities within it. Double clicking on a box provides information about the content of the relevant activity and the settings for the tool.

Hence, Figure 2, together with other supporting advice, provides a description of the teaching and learning activities for this Role Play. It contains information at three levels of description - a visual representation for the sequence of learning activities (shown), a second more detailed level of instructions/content and settings within each individual tool (accessed by double clicking), and a 


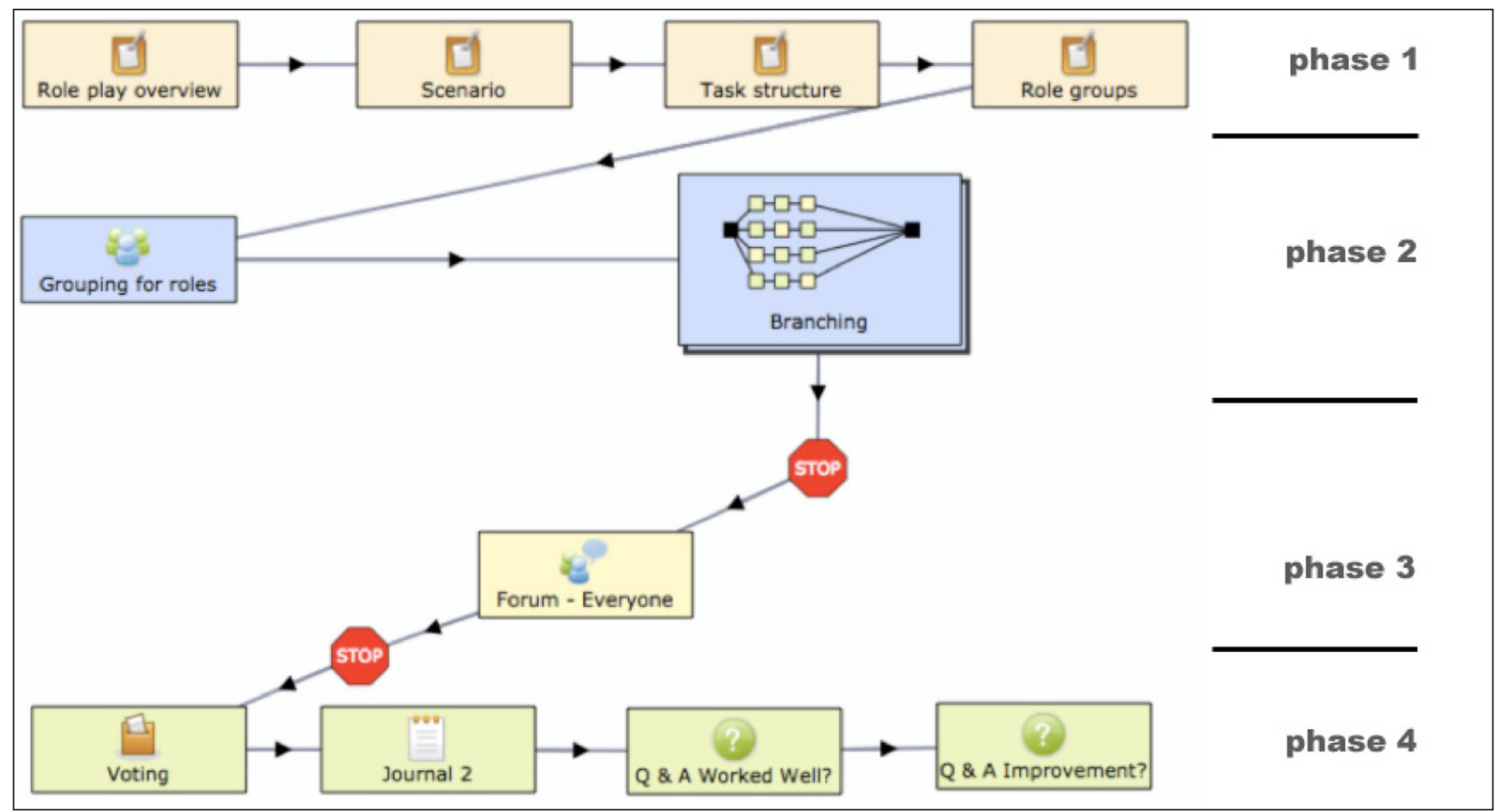

Figure 2: LAMS Authoring view of interactive whiteboards adoption Role Play, with phases added (right side).

third underlying technical description (in XML) that provides all the relevant information that a Learning Design software system needs to implement this learning design as a set of "live" activities for a group of learners (e.g., it provides the technical information about how to configure the forum for phase 3).

All of this information is contained in a single file that can be given to other educators who could then run this set of activities with their learners (given access to the appropriate Learning Design software system). This particular file is available at http://www.lamscommunity.org/ lamscentral/sequence?seq_id=690433 Even if the file is not run with another group of learners, it provides information to other educators to help them understand the structure of teaching and learning activities in the Role Play, which could assist them to implement variations of this approach (whether online or face to face).

In this example, the LAMS Authoring environment provides a framework/descriptive language for notating this learning design. There are other attempts at a descriptive framework within Learning Design research (four further examples are given in the "Conceptual Map" section below). At a technical level, there have been several XMLbased approaches (IMS LD, LAMS LD, Learning Design Language). At a written level, there are many types of lesson plan formats, as well as explicit Learning Design written formats such as LD_Lite (Littlejohn \& Pegler, 2007). From another perspective, educational patterns can be viewed as a type of written Learning Design (McAndrew, Goodyear \& Dalziel, 2006). There are also various visualisation approaches, particularly the Learning Design flow diagram from the AUTC Learning Design project. Finally, there are software systems that provide an integrated technical, "written" and visual approach, such as LAMS and COLLAGE (Hernandez-Leo et al, 2006). An example of an explicit overlap of the ideas of a Learning Design system and music notation is the "Learning Score" software developed by John Davitt and colleagues, which uses a musical score-like approach to arranging lesson activities over time. While this example is a more literal interpretation of the musical notation metaphor than is intended here, it nonetheless illustrates the power of this idea.

Each of the examples in the above paragraph is an attempt at devising a descriptive framework for teaching and learning activities that is analogous to a system for music notation. More precisely, each example is like one of the attempts at music notation prior to the development of the standard Western music notation approach that is, it captures some aspects of the teaching and learning process, but it is not yet sufficiently comprehensive or widely adopted to become a standard for "educational notation". Figure $\mathbf{3}$ gives two examples of music notation - the example on the left predates the standard Western approach but gives glimpses of what the future will be (and hence may be analogous to Figure 2), while the example on the right is based on the standard approach that has been central to Western music notation for hundreds of years (there is no analogy to this in education - not yet).

\section{Part 3: Definition Problems}

Many in the field of Learning Design currently feel that the foundational ideas and definitions are not sufficiently clear and that there is a need to create clearer conceptual foundations in order to foster the next generation of research and development. A number of meetings of experts held over several years have wrestled with these problems without clear solutions until recently (see Acknowledgements for details).

For example, the term "Learning Design" itself has a variety of meanings. In the early days of the field there was debate over whether IMS Learning Design was "the" 

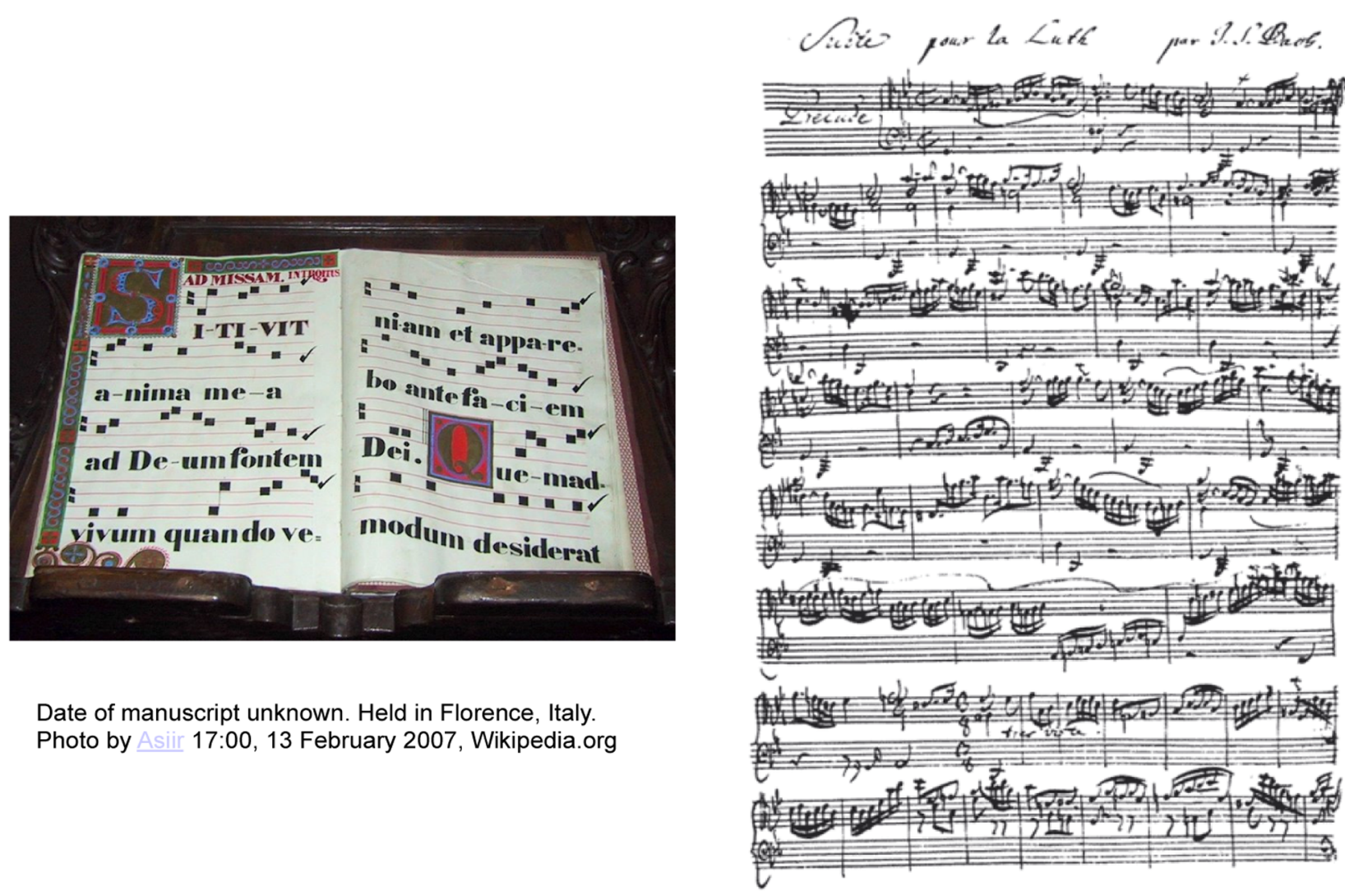

Date of manuscript unknown. Held in Florence, Italy. Photo by Asiir 17:00, 13 February 2007, Wikipedia.org

First page of the manuscript of Bach's lute suite in G Minor. Wikipedia.org

Figure 3: Examples of music notation from before the development of the standard Western notation tradition (left) and after its development (right).

Learning Design or just one example of these concepts. One early attempt to resolve this difficulty was to use a capitalised "Learning Design" to refer to IMS Learning Design and a non-capitalised "learning design" to refer to the wider concept (Britain, 2004). While this idea may have been useful in the early years, it is less useful today where many researchers wish to use the capitalised format (i.e., "Learning Design") to refer to the field as a whole, and then use "IMS Learning Design" to refer only to IMS Learning Design. We have followed this usage in this article and recommend it for the future to avoid confusion.

A related problem is that a particular sequence of teaching and learning activities that has been constructed using the ideas of Learning Design is often called "a learning design" or "a design". While this re-use of the same words to refer to both a whole field of study and a specific instance of work can be confusing, it has become sufficiently common practice that we would recommend the phrase "a learning design" or "a design" (uncapitalised and singular) for future use. We would recommend avoiding the term "learning design" (uncapitalised) for the whole field - we recommend "Learning Design" for the whole field and "a learning design" for an instance. In some contexts the words "a sequence" are used instead of "a learning design", although "a sequence" has the limitation that it may be taken to imply only a simple linear sequence. Nonetheless, "a sequence" is sufficiently common in some areas of Learning Design (especially those associated with LAMS) that it is worth noting as an alternative to "a learning design".

One of the core innovations of Learning Design software systems is that a sequence of teaching and learning activities is created independent of its implementation context (i.e., independent of a class of learners), and hence it is automatically shareable and can be used in other learner contexts. It is this characteristic that most clearly illustrates how a learning design implemented in a Learning Design software system is different from a collection of learning activities inside a class/course within a Learning Management System (LMS ${ }^{4}$ ). The learning design is created from the ground up as shareable and re-usable and then later applied to a particular class; whereas the activities in the LMS are locked to a specific class of learners, and often difficult or impossible to extract in a shareable format.

In practice, this feature of Learning Design software systems means that a learning design must be applied to a particular class of learners (which may require related tasks such as setting up learner accounts or assigning learners to a sequence; assigning specific learners to groups used within a sequence, etc.). Hence, there is a need to identify the difference between a learning design as an abstract set of activities (independent of a class of learners) and a learning design that has been implemented with a specific 
group of learners. While there has been less discussion of this issue to date, the most common phrasing for a learning design implemented with learners is "a running learning design", or alternatively "a running sequence" - these phrases are recommended for the future. To continue the musical analogy, a running learning design is equivalent to the performance of a piece of (notated) music. Another word used to describe the implementation of learning designs is "orchestration" (Prieto-Santos, Dimitriadis \& Villagrá-Sobrino, 2011). In the context of LAMS, a running sequence is also called a "lesson", but given the other connotations of this word, it is not an ideal term here.

From an educator's perspective, the creation/authoring of a learning design is different from the task of monitoring learner progress through a running learning design. From this distinction it can be noted that "evaluating" a learning design can have two (complementary) meanings. The first is that an educator could evaluate a learning design that was authored by another educator (e.g., acquired via a learning design repository). This evaluation would be based on assessing the way the activities have been constructed and the educator's opinion of their coherence and potential effectiveness - but the key issue to note is that this evaluation can be conducted independently of any data about actual learner behaviour. The second kind of evaluation is to look at learner activity data from a running version of the same learning design (or across multiple running versions of the same design where available), as this may provide additional insights into the potential effectiveness of a learning design based on learner behaviour.

The above discussion offers clarification of some existing definitional challenges within the field. At the end of this paper we will return to some broader definitional issues for the future.

\section{Part 3.1: Pedagogical neutrality and Learning Design}

While the definitional discussion above may help to clarify the meaning of key terms within the field of Learning Design, a deeper conceptual problem remains - the idea of Learning Design as a "pedagogical meta-model" (Koper, 2001), or more provocatively, that Learning Design is "pedagogically neutral".

Learning Design is not a traditional pedagogical theory like, say, constructivism. Learning Design can be viewed as a layer of abstraction above traditional pedagogical theories in that it is trying to develop a general descriptive framework that could describe many different types of teaching and learning activities (which themselves may have been based on different underlying pedagogical theories). For example, a class taught using direct instruction methods would have a different activity structure to a class taught using constructivist methods, but Learning Design seeks to provide a single notational framework that could describe both sets of activities.

It is crucial to note at this point that unlike constructivism or instructionism, Learning Design does not put forward a theory about how learners learn, and hence how teachers should teach. There is no "should" in Learning
Design as a descriptive framework - merely a description of what activities happened in the classroom or online.

By comparison, music notation provides a single framework for describing many different styles of music (Classical, Romantic, Modern, etc.). A given instance of any one of these styles could be a beautiful or mediocre example of this style. Hence, Learning Design as a "pedagogical meta-model" is attempting a similar goal as music notation - a general framework for describing many different styles/pedagogies, and any given instance of a style/pedagogy could be assessed as beautiful/effective for learning or mediocre/ineffective for learning. In this sense, the descriptive aim of Learning Design is pluralism rather than neutrality.

Going further with the music notation example, no descriptive framework is absolutely neutral - even a successful, widely used framework (such as the Western music notation tradition) will have weaknesses in certain contexts (e.g., quarter-tone singing), and there are other music notation traditions that have different strengths and weaknesses in describing musical ideas. While a widely adopted system of notation will have many strengths in representing the music of its community of origin, its success as a framework is a complex mixture of accuracy and expressiveness of representation, ease of understanding and historical factors. Hence, Learning Design could never be pedagogically neutral in an absolute sense - any system of description will have certain biases in its descriptive framework.

However, we believe that given these caveats, it is possible to conceive of a framework for describing many different types of teaching and learning activities, and that this framework could appropriately aspire towards being pedagogically neutral, even if this goal is unachievable in an absolute sense. The practical goal is a framework of sufficient accuracy and expressiveness that it can describe many different examples of teaching and learning activities (which are themselves based on different pedagogical theories). Any given instance may be an excellent or mediocre expression of a particular underlying pedagogical theory, and hence more or less effective for student learning.

While we believe that the phrase "pedagogical neutrality" can be useful as a debating point for illustrating how Learning Design is different to traditional pedagogical theories, in practice we prefer phrasing such as "Learning Design frameworks can describe a broad range of teaching and learning activities" so as to avoid unnecessary consternation among colleagues who experience visceral reactions to "pedagogical neutrality". Hence, we recommend the less provocative formulations for future general purpose discussion of Learning Design, while acknowledging the occasional use of the more provocative form in the narrow case of debates that compare Learning Design to traditional pedagogical theories.

\section{Part 4: A Learning Design Conceptual Map}

Descriptive frameworks for teaching and learning activities are one of the core innovations of Learning Design, but there are many related issues. Any particular 
representation of a learning design can also include advice about the design, including advice about how the design was created (and hence how it could be changed) and also advice about implementing the design with learners. Another central element is that of sharing - as the reason for describing good teaching ideas is to propagate these ideas among educators, in order to ultimately improve teaching and learning widely.

But even these core concepts are only a small part of the wider field of Learning Design. In Figure $\mathbf{4}$ we have tried to capture the broader education landscape and how it relates to the core concepts of Learning Design. We have called this a Learning Design Conceptual Map (LD-CM). For the sake of clarity, we refer to a box in the LD-CM as a "component" and an item within a box as an "element".

The arrows provide one view of how the different elements interact in the process of designing and implementing teaching and learning activities, but there are other interactions both within and between the elements of the LD-CM - however, to attempt to note all possible arrows would make the Map unwieldy. But this is not to discount the importance of other connections between parts of the Map, for example, an arrow from Learner Responses to Educational Philosophy could indicate the ways in which learner responses to learning experiences can shape the educational philosophy of an educator, and how this could change how an educator designs future learning experiences.

\section{Challenge}

Our overall statement of the challenge is "creating learning experiences aligned to particular pedagogical values and objectives". Just as the Learning Design descriptive framework seeks to support many different pedagogical approaches, we have similarly tried to phrase our vision of the general educational challenge in a way that is applicable to many different contexts regardless of the particular pedagogical approaches of that context.

In practice, the actual pedagogical approaches and learning objectives will be determined by the Characteristics and Values of institutions, external agencies and educators (and indirectly, learners), together with the relevant Educational Philosophy and Theories and Methodology that are appropriate for a given educational context. Hence the top left section of the LD-CM provides a structure for analysing the broader educational context and how it impacts on representations of teaching and learning activities - these three components are discussed below.

We note that some approaches to education sector transformation start with an assumption that educators need to be "fixed" or even in some technology discussions, "removed". By comparison, the field of Learning Design focuses on educators creating great teaching ideas and sharing these with their colleagues, who in turn adapt these ideas to suit their local teaching context, and potentially share back adapted or improved versions of

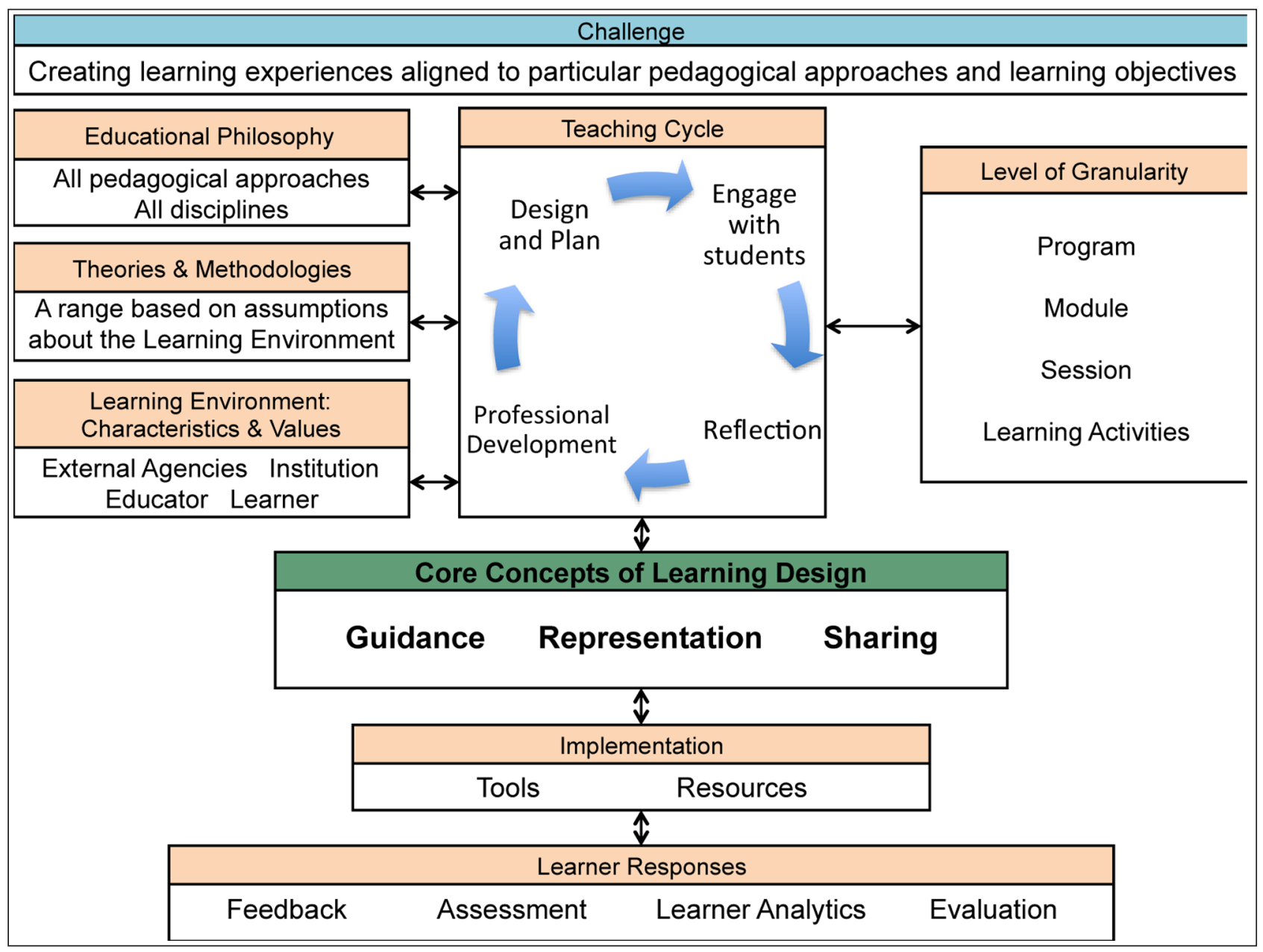

Figure 4: A Learning Design Conceptual Map. 
the original idea. While a shared learning design might be used "as is" if it is a perfect fit for the local context, the usual expectation is that an educator who adopts a learning design will still need to adapt it to suit the particular needs of his/her learners. Hence the re-use of learning design is not a mechanical implementation process, but rather a creative process where educators use professional judgement to align a good teaching idea from elsewhere with the unique needs of their context. Going further, this implies that Learning Design software should empower a typical educator to easily edit a learning design, rather than requiring specialist technical skills or assistance from technical staff.

Educators are central to Learning Design as creators, sharers, adapters and improvisers, working together in professional communities of practice. As a model of education sector transformation, it is a model led by educators for educators.

\section{Educational Philosophy}

This component of the Learning Design Conceptual Map is to note the explicit or implicit pedagogical theories that underlie decisions about teaching and learning. This most often has an impact via the choices of educators, but policy decisions at higher levels (such as educational institutions and external agencies such as government education departments or professional bodies) can also affect educational philosophy. For example, university degree validation documents often require statements regarding the educational approach taken to the design and delivery of courses, and these may be influenced by policy and strategy.

Some examples of pedagogical theories include constructivist approaches, cognitive and developmental approaches, instructionism/drill and practice-style approaches, connectivist approaches and others. More detailed discussion of pedagogical theories, effective teaching and Learning Design is provided at the end of this paper.

This component also notes that Learning Design is applicable to all discipline areas. While the structure of particular learning designs may vary from discipline to discipline, the underlying concepts of Learning Design are relevant to all content domains.

\section{Theories and Methodologies}

There are a wide range of theories and research methods that are used to guide decisions about teaching and learning activities, as well as to evaluate the impact of those decisions. This includes theories about how people interact, about how institutions affect people's behaviour, theories of motivation and incentives, etc. These include theories such as Cultural-Historical Activity Theory, Communities of Practice, Actor-Network Theory and Cybernetics and Systems Thinking (see Conole, 2013, for a review of these theories in relation to Learning Design).

Most importantly, there are many different types of research methods used in education, including quantitative and qualitative research, action research, designbased research, experimental control studies, case studies, ethnography, etc. Differences in research methods lead to different kinds of evidence for educational effectiveness, which in turn is used to support different kinds of pedagogical approaches, which ultimately affects the dayto-day decision-making of educators, and the policy directions of educational institutions.

\section{Learning Environment: Characteristics and Values}

This component of the Learning Design Conceptual Map can be used to describe how the context for learning affects the design of teaching and learning activities. The title draws attention to how both the characteristics and values of external agencies (such as government and professional bodies), institutions, educators and learners are relevant to understanding an educational context.

An educational institution can have formal education structures and accreditation (e.g., a university degree), or it may have more informal structures (e.g., a community learning group such as computer skills for older people). For example, a university's focus on knowledge testing in formal exams in order to pass courses for a degree differs from a focus on practical abilities/competencies, such as the ability to use a computer where there is no external assessment/certification. Explicit and implicit moral, political and spiritual values can have an impact on a given learning environment via educational institutions, as well as via educators and learners. In addition, institutional characteristics include the physical and virtual environments available for teaching and learning. The institution's characteristics and values typically impact teaching and learning through affordances and constraints on the behaviour of educators and learners.

Educational institutions rarely have complete freedom to allow educators to teach as they wish - it is more common for institutions to be affected by external agencies that constrain and direct their teaching, be it government education departments or industry and professional bodies. It is not unusual for institutions to be affected by many different external agencies, and the complexity of overlapping constraints and directions from multiple agencies is one of the growing modern pressures on institutions and educators.

Educators bring different characteristics and values to their decision-making about teaching and learning activities. This includes the quantity, and style, of teacher training that has been received, past experiences as a learner, the kind of classroom/online teaching experience of an educator, the role of other educators as peers and mentors, the self-perception of the educator's role as expert/ facilitator/provocateur, the educator's values about the kind of learning that is important (and unimportant) for his/her learners, etc.

Learner characteristics and values include responses to teaching and learning activities (e.g., whether learners are comfortable with debate, or questioning the ideas of their teachers), their past learning experiences and how they shape current behaviour, their own values about what matters (and what doesn't) in their education, their levels of motivation and engagement, their goals for their future, etc. These characteristics operate not only at the individual level, but also in larger clusters, such as the "student culture" of a particular class or a whole educational institution, and also wider cultural approaches to education, such as national attitudes. 
Of particular importance to recent educational reforms are the learner characteristics of developing graduate attributes $/ 21^{\text {st }}$ Century skills, such as critical thinking, teamwork, communication, inter-cultural understanding and creativity. A related skill is the development of critical reflection on life and work with digital technologies - often referred to as digital literacies - and the wider range of digital responses that learners can produce in today's world, such as creating a presentation, a website or a movie, rather than simply writing text for an essay.

There are many complex interactions among external agencies, institutions, educators and learners in terms of characteristics and values. For our current purposes, it is simply worth noting that different assumptions within this part of the LD-CM will have different impacts on how teaching and learning activities are planned and delivered, and how learners respond to these activities.

\section{Teaching Cycle}

This component of the LD-CM acknowledges how different stages in the Teaching Cycle can impact on the design of teaching and learning activities. Obviously, how an educator designs and plans a set of activities is crucially important, and this is a central focus of Learning Design. But the LD-CM also draws attention to how educators engage with learners, such as adapting their teaching "in the moment" to the changing dynamics of the classroom, or responding asynchronously to learners in an online discussion forum. Indeed, one of the most frequent concerns about online education is the loss of non-verbal cues about learner reactions to teaching that otherwise inform adaptation "in the moment". This example draws attention to the more general issue of how the act of teaching sometimes plays out differently to how it was planned beforehand.

The dimension of adaptation or improvisation of teaching "in the moment" has been weak in Learning Design to date, particularly where Learning Design software systems struggle to change a sequence once it is running. However, any current technical difficulties in coping with this requirement should be of secondary importance - the skills and techniques that educators bring to adaptation "in the moment" are of great importance to teaching and learning. It is worth drawing attention to this historical weakness in Learning Design, as the ability to adapt teaching in the moment is central to the self-image of many educators, and hence a perceived lack of emphasis on this aspect of teaching and learning has led some educators to dismiss Learning Design in the past.

Reflection on teaching during and after the event is also of significant importance to future design decisions understanding what went wrong in an unsuccessful class can change planning in the future. A more long-term view of this process of reflecting on teaching is captured in the "Professional Development" element, also sometimes called "Professional Learning", which would contain both formal Professional Development courses as well as the long personal journey of gaining experience as an educator, and how this influences subsequent Teaching Cycles of designing and engaging with learners.

\section{Level of Granularity}

This component of the LD-CM illustrates different levels of granularity in the design of teaching and learning activities, such as how individual Learning Activities build up to sequences or Sessions. Collections of Sessions over time make up larger Modules (like courses), and Modules often combine to larger Programs of learning, such as a degree or a year (or set of years) of school education.

These distinctions will at times have fuzzy boundaries and different terminology (particularly across different education sectors - e.g., universities versus schools), but the important issue for this Map is that different kinds of decisions are typically made at each level. Individual Learning Activities involve decisions such as the phrasing of a reflective question (e.g., open or closed), the layout of an online resource and the structure of quiz items. Sessions tend to be collections of activities (be they sequential or other non-linear structures), with the key focus being the learning objectives(s) of a set of activities, and the rationale for the choice and arrangement of Learning Activities to achieve this objective. Many innovative teaching strategies, such as Role Plays, Problem-Based Learning, PredictObserve-Explain, WebQuests, etc., are sets of Learning Activities that have a particular sequential structure.

Decisions at the Module level relate to how Sessions relate to a larger unit - such as how the weekly Sessions of lectures and tutorials are structured to cover the content of a course in a typical university setting, or how a set of different sequences of Learning Activities contribute to a larger unit of work over a number of weeks/ months in a school. Program level decisions often include high-level progression concepts, such as course pathways within degrees (and their prerequisites), or the structure of Modules over a year in a school. It is also worth noting that broad learning objectives at Program and Module levels (such as $21^{\text {st }}$ century skills) may cascade down into particular learning objectives at the level of Sessions and Learning Activities.

\section{Core Concepts}

At the heart of the LD-CM are the core concepts of Learning Design - most centrally the idea of a descriptive framework for representation and visualisation of teaching and learning activities - "educational notation". This element is complemented by guidance and sharing.

\section{Guidance}

Guidance covers the many ways that educators can be assisted to think through their teaching and learning decision-making, in particular, how they can understand and adopt new, effective teaching methods. In some cases guidance is incorporated into the representation (e.g., patterns), whereas in others it is a complement to the representation, for example:

- websites with information on teaching ideas and tools (e.g., the Phoebe Pedagogic Planner, Masterman \& Manton, 2011),

- software systems that seek to guide educators through a reflective process about their teaching (e.g., the London Planner/Learning Designer), 
potentially including artificial intelligence to offer suggestions during the process,

- collections of templates of effective teaching strategies and accompanying advice (e.g., LAMS Activity Planner),

- workshop processes for guiding groups of educators in reflective planning of future teaching (e.g., Viewpoints project, Open University Learning Design Initiative), and

- formal teacher training/professional development.

Given the focus of the field of Learning Design on sharing and re-use, an important aspect of guidance is information to accompany any shared learning design about its context of use, and how it might be adapted for another context. This may include metadata about the learning design, covering issues such as the educational context of its original use (e.g., discipline, age group, timeframe, country, etc.), its learning objectives and pedagogical rationale, past implementation experiences with learners, suggestions for adaptation and so on. The point is to provide sufficient guidance to aid in local implementation when an educator considers using/adapting a learning design from another context. Further details about processes of sharing are given in the Sharing section below.

\section{Representation}

As noted above in relation to Figure 3, the field of Learning Design is yet to develop a widely accepted framework for representation of teaching and learning activities. However, aspects of a number of projects provide indications of how this framework might be conceptualised. Figure $\mathbf{2}$ provides an example from the LAMS Authoring environment that draws attention to the flow of different kinds of learning activities over time in a visual format. Another example of a visual format for illustrating the flow of activities over time is the flow diagram from the AUTC Learning Design project - Figure $\mathbf{5}$ provides

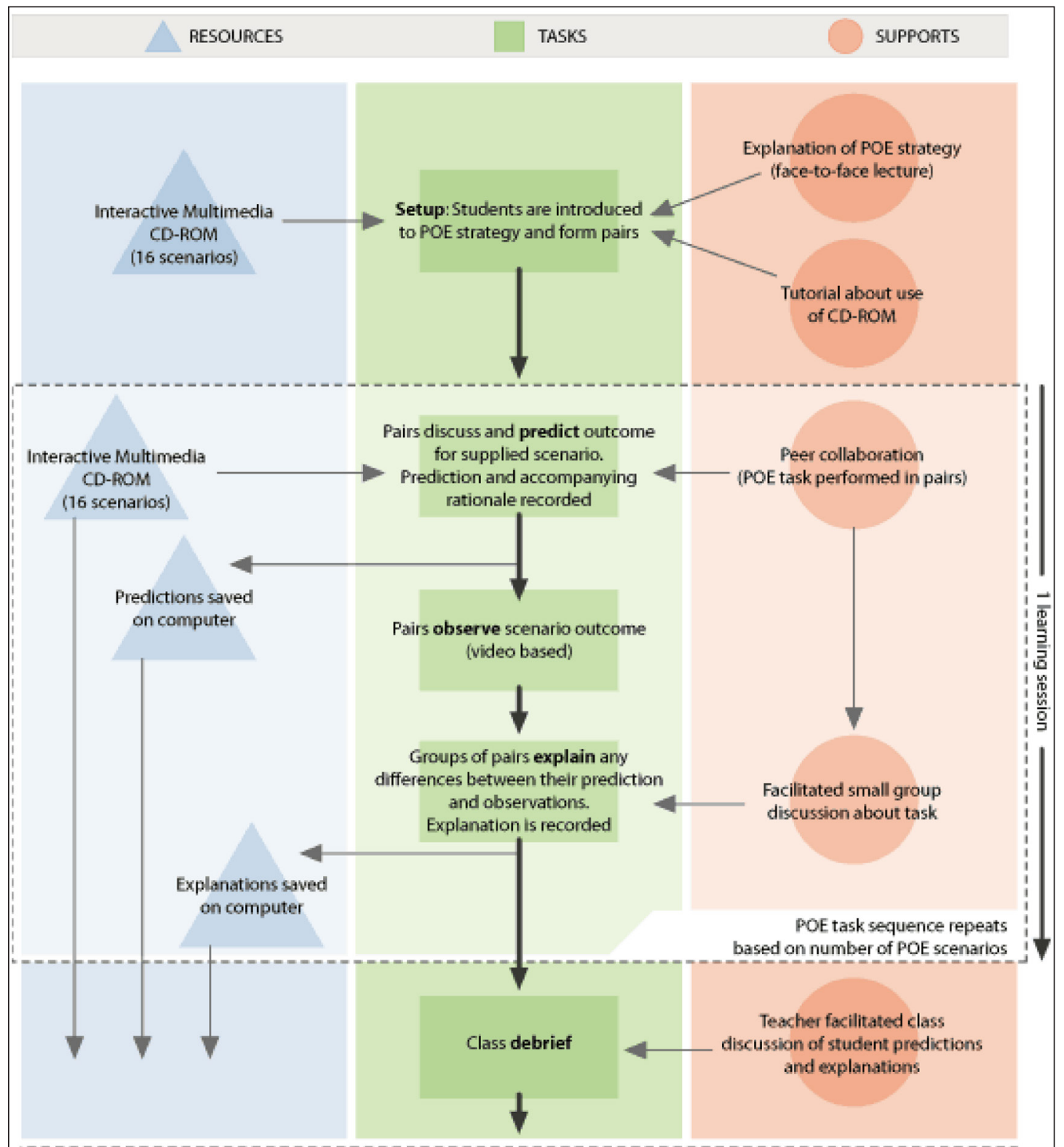

Figure 5: A "Predict - Observe - Explain" teaching method described using the AUTC Learning Design project flow diagram. 
an example of this diagram for describing a "Predict Observe - Explain" teaching method (AUTC Learning Design, 2002).

Another kind of representation is educational patterns, drawing on research on patterns in disciplines such as architecture and software development. Patterns use a particular form of structured text, and may also include a visualisation, such as the example in Figure 6 for a jigsaw teaching method (from Dimitriadis, 2012).

A fourth kind of representation is the timeline and pie chart views in the Learning Designer (previously named the London Planner). In this representation, the learning activities are analysed in terms of the type of learning that occurs in each activity (including the potential for multiple types of learning to occur in one activity). This approach is based on a conceptual classification of types of learning into five categories (also known as pedagogic descriptors): Acquisition, Discussion, Inquiry, Practice and Production. This approach allows for computational analysis of the types of learning occurring across learning activities (as opposed to analysis of simply the type of digital tools selected, as with LAMS). This is a promising area for future Learning Design research if agreement on a set of pedagogical descriptors can be achieved. Figure 7 is based on an example about evaluating energy use from Bower, Craft, Laurillard and Masterman (2011).

A final, different example of a representational approach is the Open University Learning Design Initiative (OULDI) "Course Map" view (see Conole, 2012), which is a representation primarily at the "Module" Level of Granularity (as compared to the previous four examples, which were primarily at the Learning Activities and Session levels). This

\section{Pattern 1.1 JIGSAW **}

... within a collaborative learning scenario in which SCRIPTED COLLABORATION (pattern 11 from (ELEN, 2005)) is seen as a remedy for situations where free collaboration does not lead to learning, it may be necessary to plan how groups will perform a set interrelated activities. This pattern gives the organization of a collaborative learning flow for a context in which several small groups are facing the study of a lot of information for the resolution of the same problem.

If groups of students face resolution of a complex problem/task that can be easily divided into sections or independent sub-problems, an adequate collaborative learning flow may be planned.

The flow of collaborative learning activities to be followed in order to solve a complex divisible task should promote the following educational benefits (Aronson \& Thibodeau, 1992; Clarke, 1994; Johnson \& Johnson, 1999):

- To promote the feeling that team members need each other to succeed (positive interdependence)

- To foster discussion in order to construct students' knowledge

- To ensure that students must contribute their fare share (individual accountability)

However, the solution for structuring collaboration in order to tackle this problem may be complex and probably more appropriate for collaborative learning experienced teachers and learners. It may be best suited for the end of the semester when the students are comfortable with group work.

Therefore:

Structure the learning flow so that each student (individual or initial group) in a group ("Jigsaw Group") studies or work around a particular sub-problem. Then, encourage the students of different groups who study the same problem meet in an "Expert Group" for exchanging ideas. These temporary focus groups become experts in the section of the problem given to them. At last, students of each "Jigsaw group" meet to contribute with its "expertise" in order to solve the whole problem.

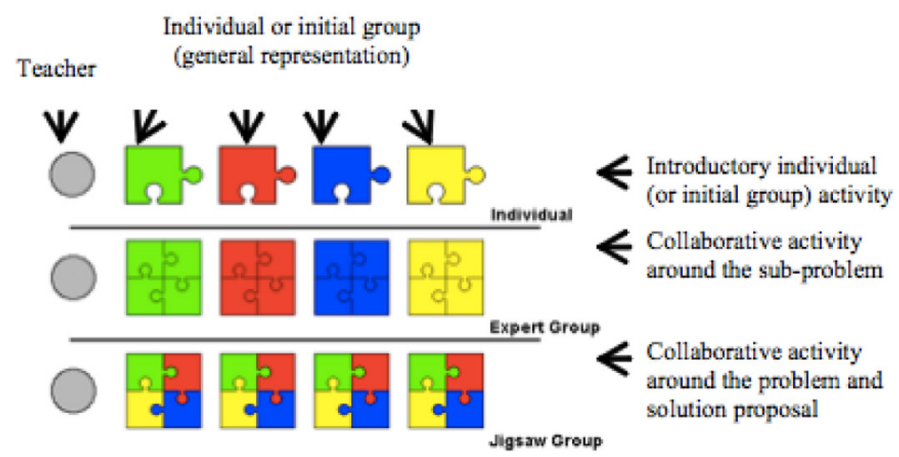

Figure 6: Part of a jigsaw teaching method described using an educational pattern (NB: not shown are sections at the end of this pattern for "Patterns that complement this pattern" and "Patterns that complete this pattern"). 


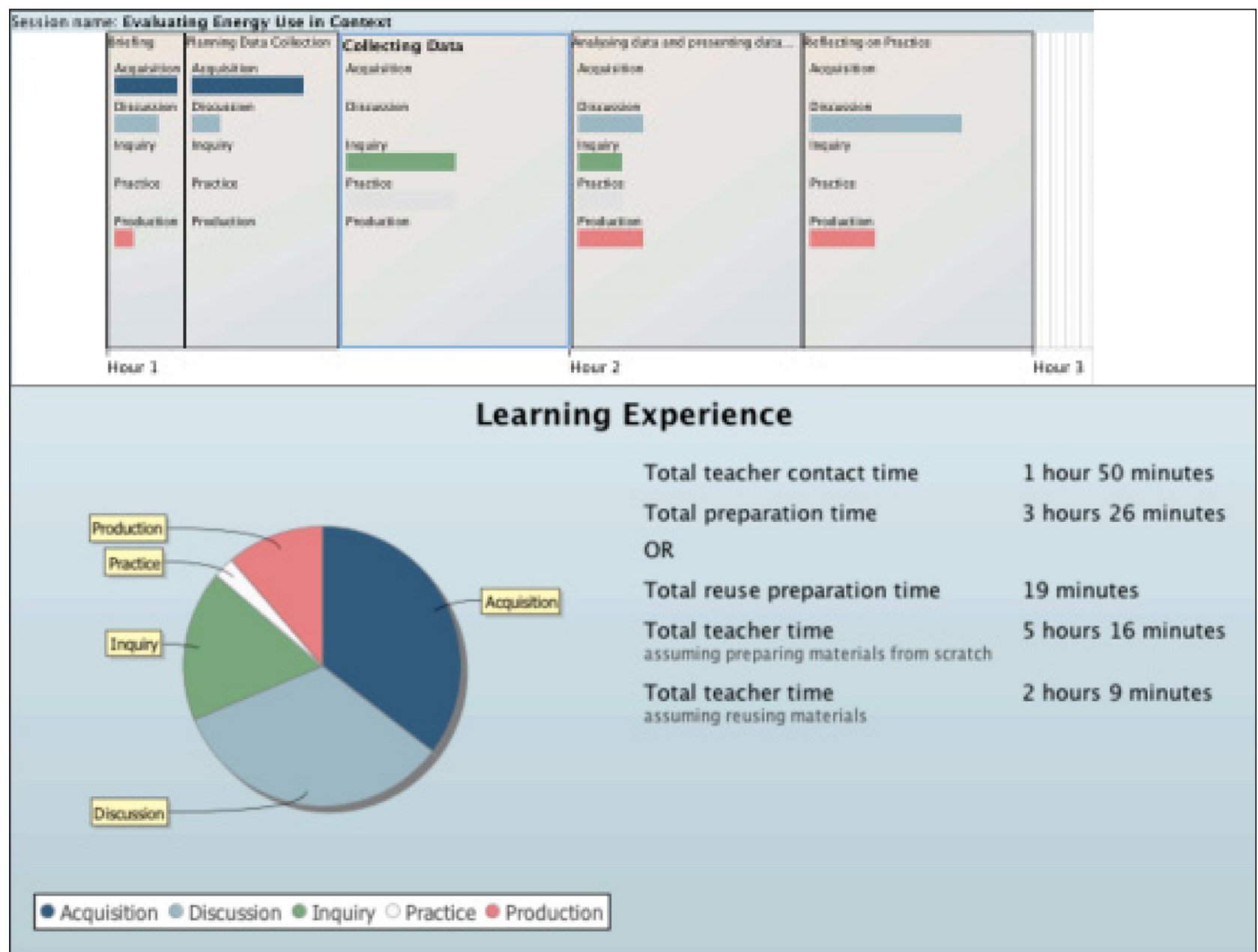

Figure 7: Timeline and pie chart views of analysis of learning activities in the Learning Designer for a sequence on evaluating energy use.

representation draws attention to the components of an overall university course/unit, and how tools/resources and roles/relationships relate to the different course aspects of Guidance and Support, Content and Experience, Reflection and Demonstration and Communication and Collaboration. It does not describe sequences of activities like earlier examples (activities are described elsewhere in the OULDI approach, including some similar ideas to Figure 7) instead, it provides a more holistic view of different types of activities across the whole unit/course - see Figure 8.

Before leaving this section, two additional points are worth making. First, an interesting difference between patterns and a software-based learning design (such as a LAMS sequence) is that a pattern provides ideas/guidance for a teaching method, but how these ideas are used in practice still requires a "creative leap" by the educator; whereas a LAMS sequence (if it contains relevant content) could potentially be used "as is" - no creative leap may be needed. There are potential benefits and challenges in each case - a pattern requires significant additional work for implementation, but this work should help to ensure the pattern is appropriate to the immediate learner context; a LAMS sequence with relevant content could rapidly be used as is, but if it is used without sufficient regard for the immediate context, a pre-built sequence from another context may not be a good match for local learner needs.
The normal expectation would be that any re-use of a learning design requires careful professional judgement by an educator to determine how best to adapt and then implement a teaching idea to suit the local context.

Second, there is a tension between the extent to which a descriptive framework rapidly conveys the essential teaching idea(s) of a learning design compared to conveying the detailed teaching and technical information needed for implementation ("orchestration"). This can be described as a tension between "beauty and precision" in descriptive languages (Derntl, Parrish \& Botturi, 2010).

In summary, Learning Design projects have developed a number of different ways to represent/visualise teaching and learning activities that hopefully provide a glimpse of a future widely adopted framework for educational notation. It may be that a single dominant representation will be widely adopted in the future (as in Western music notation) or it may be that multiple diagram types will be needed (such in the Unified Modelling Language in software development). It may even be that new technologies, such as animations, will provide new approaches to representation that do not have a simple written analog. For a promising early example of this idea, which uses animations to represent assessment information across a semester at a Module and Program level, see the "Map My Programme" project (Walker \& Kerrigan-Holt, 2012). 


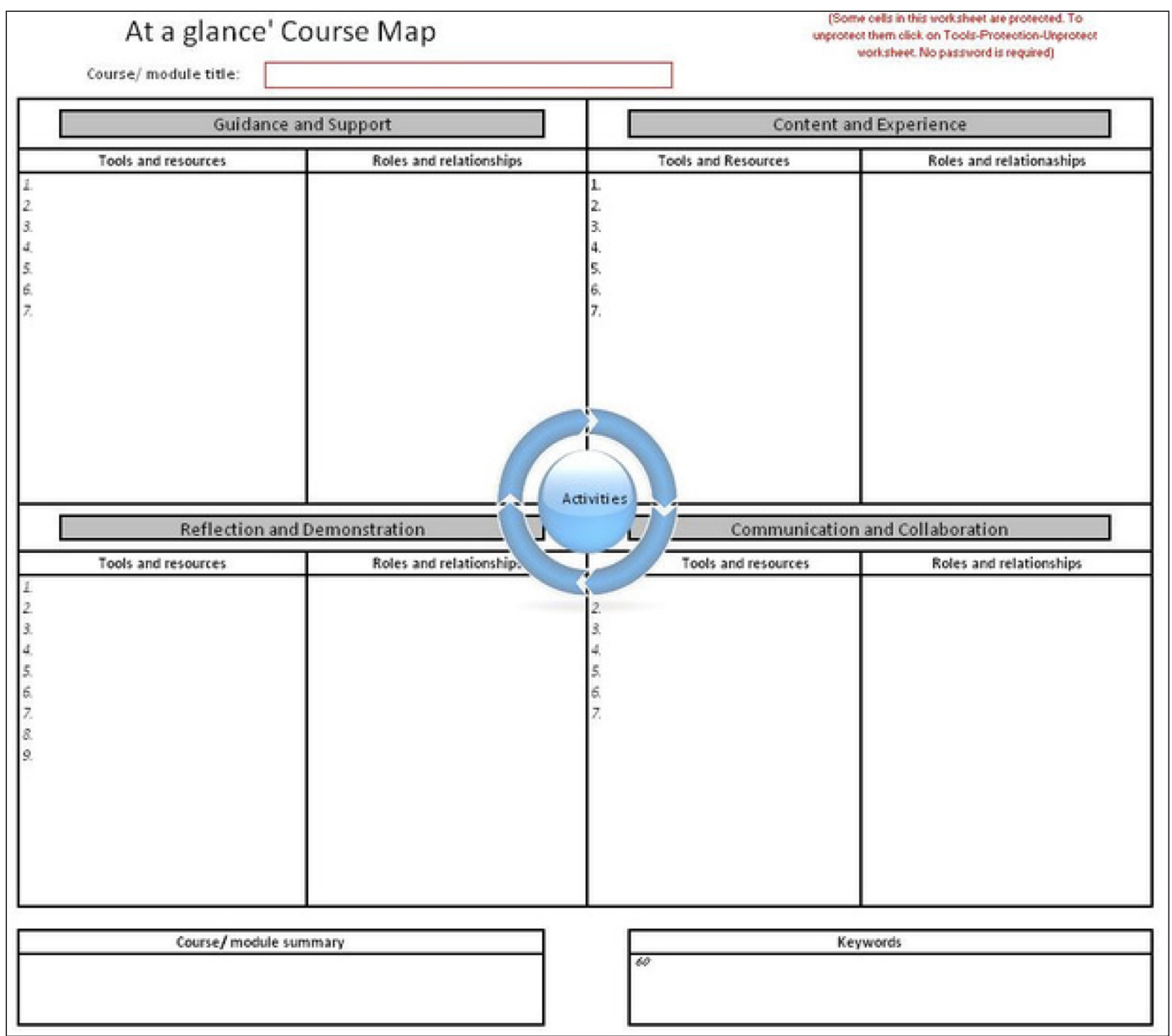

Figure 8: Course Map template (empty) from the Open University Learning Design Initiative.

\section{Sharing}

The "Sharing" element draws attention to the driver behind representation - the propagation of good teaching ideas from one educator to another. Learning Design has a strong history of sharing, including the use of online repositories of learning designs (e.g., the LAMS Community) and communities for discussion of teaching ideas among peers (e.g., Cloudworks). Sharing in Learning Design is often under open educational licenses (such as Creative Commons licenses), and hence is part of the wider movement of Open Education, and related movements in open source software and open content.

Indeed, a case can be made that Learning Design is "open source teaching", in the sense that the open sharing of descriptions of teaching activities is like sharing the "source code" of teaching, and where these ideas are developed and improved over time by communities of educators, then there is genuine argument for the phrase "open source teaching". And this idea supports one of the striking possibilities of Learning Design - the potential to take teaching strategies from one discipline (e.g., PBL in medicine) and propagate them to other disciplines by capturing the underlying pedagogic essence of the teaching strategy in a learning design (separate from any discipline content) in order to explore the potential use of this teaching strategy in a different discipline context.

An agreed representation is only one part of the complex phenomenon of sharing - there are many social forces at work that foster and inhibit sharing. By comparison, the adoption of music notation was driven not only by its conceptual elegance and usefulness, but also through social practices of music teaching using the notation, as well as informal networks among musicians who propagated this notational approach when it first appeared. Similarly, any widespread acceptance of an educational notation system will arise from a complex mixture of usefulness, social propagation and serendipity. More research is needed on the factors that foster, and inhibit, practical sharing of learning designs.

\section{Implementation}

This component of the Learning Design Conceptual Map draws attention to different Tools and Resources that are required during teaching. This could include physical tools for classroom activities (whiteboard, flipchart, pens) as well as educational resources such as articles and 
videos. In online contexts, activities may require tools such as discussion forums, wikis, quiz systems, etc., and resources such as websites and online videos.

In the case of Learning Design software systems, activity tools are a part of the overall software. A special feature of activity tools in Learning Design software systems is that they need to be capable of being configured by a learning design. That is, when an educator obtains a learning design file, and implements it in a local course, the file contains technical instructions to the Learning Design software system about how to configure the various tools required (e.g., at step 3, provide a discussion forum with two threads, with the discussion topic for thread 1 as "How is X similar to Y?" and thread 2 as "How is X different from Y?").

This requirement for Tools to be capable of receiving "injection" of external content and configurations from a learning design file has proved a far more demanding technical requirement for Learning Design software systems than was initially anticipated, and is one of the reasons for difficulties in creating fully functional Learning Design software systems.

A related requirement is the need for a sequencing engine to facilitate the progress of learners through a suite of activities, and for activity tools to be "sequencing aware" - that is, to be able to designate completion of an activity to a sequencing engine in order to allow for learner progress through a sequence. As noted earlier, this should not be taken to mean only simple linear sequences - systems such as LAMS provide features for multiple pathways and set of activities which can be completed in any order and which can be revisited multiple times. These demanding technical capabilities are absent from most (if not all) current Learning Management Systems, which helps explain the need for separate Learning Design software systems (which can then be integrated into LMSs).

\section{Learner Responses}

We have chosen the title "Learner Responses" to capture many different types of information about student learning, such as learning outcomes, competencies, skills and understanding. While formative and summative Assessments are typical in many educational contexts (and the wider literature on these topics is all relevant here), Learning Design draws attention to a wider view of responses from learners. This includes Feedback, such as the real-time learner reactions to teaching that an educator may use to change teaching "in the moment" (see Teaching Cycle above). It also includes more structured Evaluation of teaching, such as course surveys, which may play an important role in future improvements to teaching practice.

But Learning Design software systems provide an opportunity for deeper tracking of learner activity, as every step for every learner is recorded as a by-product of the use of technology to manage the sequence of activities. This includes not just learner responses to activities but also time taken on each activity. This allows for a richer analysis of learner behaviour at all stages of the teaching and learning process, rather than just at points of assessment, or simply counting the number of mouse clicks of a learner within a LMS course. It also allows richer comparisons within a group of learners (e.g., what are the final quiz scores of learners who spent above average time in the discussion forum?). This dimension of Learning Design allows for rich Learner Analytics based on a new kind of "big data", and this illustrates how big data about collaborative learning could be used to extend the current approaches to massive open online courses (MOOCs). It could also help to avoid one of the current pitfalls of Learner Analytics research where the outcome of data analysis is simply the "discovery" of the pattern of activities that constituted the educator's lesson plan in the first place. In Learning Design software systems, the structure of activities is embedded with the learner analytics data, allowing for more profitable uses of this data for educational research.

As with Assessment, the wide literature on formative and summative Evaluation is relevant to Learning Design. A perspective on evaluation of special relevance to Learning Design is that learners are increasingly interested in the teaching methods used in their courses, and some will intentionally choose courses and institutions that use (or do not use) certain teaching methods (such as Problem Based Learning in medicine). The willingness of learners to make choices about their future study based on their evaluation of different learning designs across courses or institutions illustrates that it is not only the evaluation of learning designs by educators that will affect future decision-making - learner evaluations of learning designs will increasingly affect the decision-making of institutions and educators.

\section{Part 4.1: Applying the Learning Design Conceptual Map to educational theory and practice}

The Learning Design Conceptual Map provides a wider educational context for Learning Design representations, but it can also be used to explore how other educational theories/practices relate to Learning Design, and to each other. While a thorough discussion of any one of the following examples would require more space than is available here, we provide some initial indications of how different theories/practices can be conceived of as "overlays" onto the LD-CM.

For example, Diana Laurillard's "Conversational Framework" (Laurillard, 2002) is a model for understanding how educators and learners interact in terms of understanding a discipline's theory as well as practical tasks. The model focuses on interactions between educators and learners at both theory and practice levels, and also how learners reflect on theory and practice internally, as well as how educators reflect on their teaching of theory and practice as a result of their interactions with learners.

In the context of the LD-CM, a given instance of teaching using Laurillard's Conversational Framework could be notated using a Learning Design representation. This could be accompanied by guidance for educators on using the Conversational Framework in this instance of teaching, and sharing of this instance with others. More broadly, the Conversational Framework has a particular focus on several elements of the LD-CM: Sessions and Learning 
Activities within Level of Application; Reactions to teaching and potentially Assessment in Learner Responses; and particularly the Teaching Cycle where Engaging with Learners and Reflection are affected by interactions with learners (in both theory and practical areas of the relevant discipline). Many more comments could be made about the Conversational Framework and the Learning Design Conceptual Map, but for current purposes, the point is to draw out how particular parts of the Map are significant for the Conversational Framework.

A different example is the "TPACK" Framework (Koehler \& Mishra, 2009) about the technological, pedagogical and content knowledge used by educators when they design learning activities. Teaching based on the TPACK Framework could be described using the LD-CM, e.g., the level of application would be primarily at the Module and Learning Activity levels, and while the whole Teaching Cycle is relevant, there would be a greater focus on a longer-term process of professional development in understanding the TPACK Framework. As TPACK places a particular emphasis on technology, it would also focus on the way that Tools are used within the Implementation component, and differences in how educators use technological tools according to their technological knowledge.

A more challenging example to consider is the broad field of Instructional Design. Some examples of instructional design tend to focus mostly at the Learning Activity level, together with some focus on Sessions in terms of the sequencing of Learning Activities. But the underlying meaning of teaching and learning here can be quite different to the previous two examples, as some Instructional Design approaches only address single-learner contexts where no peers or educators are present (e.g., the Shareable Content Object Reference Model - SCORM technical standard that is the basis of much e-learning courseware). SCORM constrains the type of activities that are possible (e.g., no collaborative activities), which would affect the nature of the representation as well as the choice of tools. The Teaching Cycle looks quite different for SCORM courseware, as there is no educator present in the teaching step, so all decisions are made during preparation. Changes for the future are possible based on Learner Responses, but these are typically limited to assessment such as quiz scores, and in some cases more advanced learner analytics such as time on task and cursor movements on screen.

Perhaps most significantly for a single-learner Instructional Design approach such as SCORM, it tends to have a different set of pedagogical assumptions, together with a focus on different kinds of research data to support these pedagogical assumptions. There is a need for a deeper exploration of how Learning Design relates to Instructional Design, and we hope that research on descriptive frameworks together with the LD-CM can assist in describing connections and differences between Learning Design and Instructional Design - there is much work yet to be done. Ultimately, we believe that Instructional Design is one subset of the possibilities covered by Learning Design, although it is also worth noting that Instructional Design has a more developed set of theory and practices than Learning Design at the current time.

There are many other educational theories and practices that could be analysed using the Learning Design Conceptual Map, and it may be that some of these will draw attention to significant omissions from the LD-CM, leading to an evolution of the LD-CM in the future. For our present purposes, though, we seek to illustrate how a given theory or practice can be analysed as an "overlay" onto the LD-CM, and how different overlays can be compared to each other to better understand their similarities and differences. This approach of visualising overlays to the LD-CM is illustrated in Figure 9 by highlighting areas of particular significance within the LD-CM for Laurillard's Conversational Framework compared to areas of significance for SCORM in Figure 10. Where two overlays regard the same area as significant (e.g. Education Philosophy and Tools in Figures $\mathbf{9}$ and 10), it is important to investigate similarities and differences in how this area is interpreted in each approach.

We believe these comparisons will also benefit from using a Learning Design representation of one or more concrete instances of teaching and learning activities (based on the given theory/practice) in order to better explicate similarities and differences in classroom practices arising from theoretical differences. The combination of broad analysis of pedagogical approaches (using LD-CM overlays) combined with detailed analysis of concrete examples of teaching and learning (using a Learning Design framework) will foster clearer understanding of differences in theory and practice in education.

\section{Part 5: Learning Design and Pedagogical Theories}

Having earlier dealt with the narrow question of pedagogical neutrality, and then provided a conceptual map of the broader landscape for Learning Design, it is worth returning to the thorny question of pedagogical theories and Learning Design. A notational framework for describing examples of many different pedagogical approaches may be of interest to a small audience of theoreticians who are fascinated by the challenge of abstract representation. However, the great majority of educators would be interested in a descriptive framework in order to help them teach more effectively.

By comparison, it would be possible to notate almost any musical performance (no matter how unpleasant), but few people would be interested in this notation purely as a challenge to the capabilities of the notation system. Rather, writing down musical ideas is a way to convey great music from one person to another over time and space. An abstract framework for notation is itself of little interest to most musicians - what matters is what it conveys, not how it does it. We remember the names of great composers, not the names of those who developed music notation.

The ultimate rationale for Learning Design is that it can convey great teaching ideas among educators in order that learners may learn more effectively. This improved 


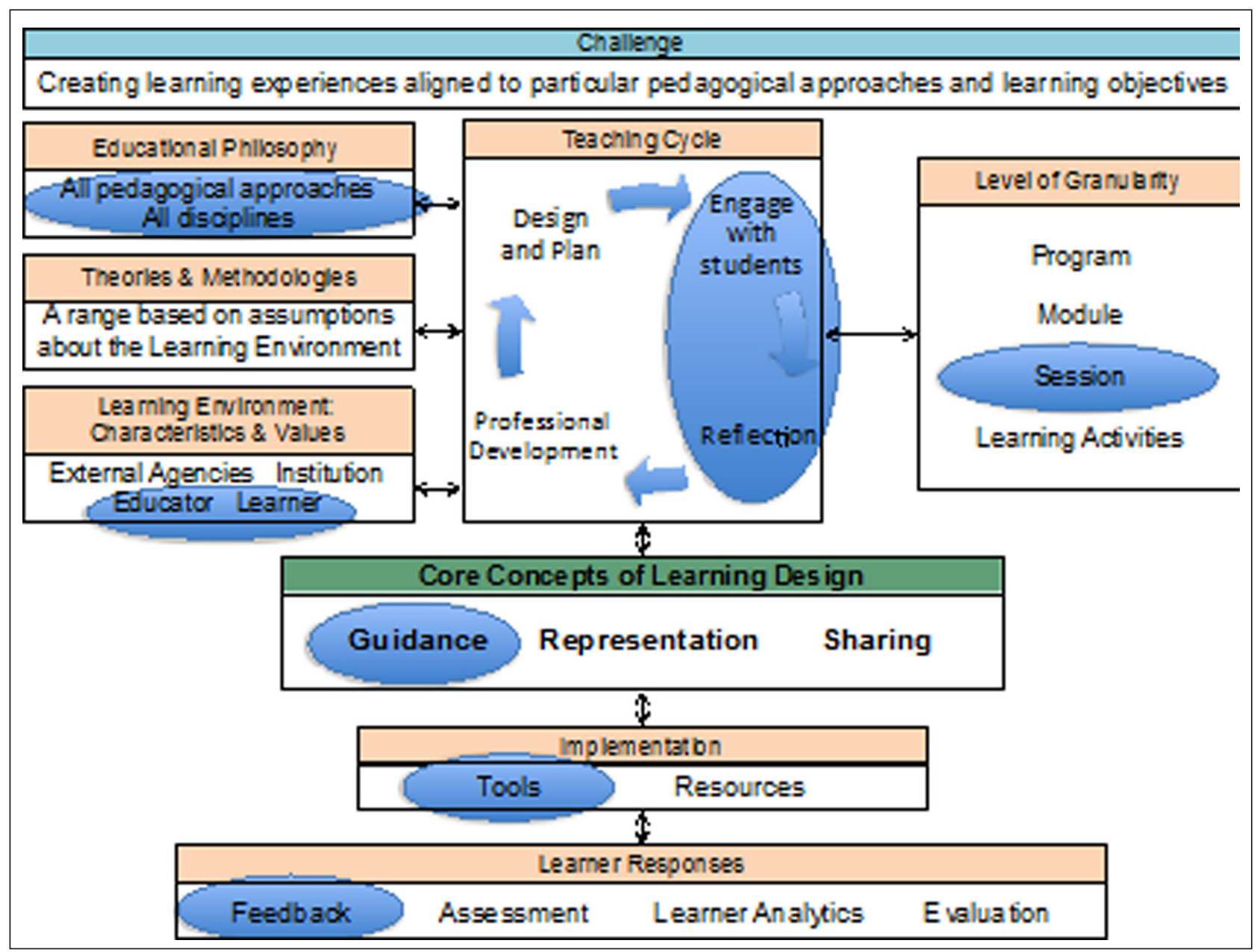

Figure 9: Example of LD-CM overlay for significant areas of interest in Laurillard's Conversational Framework (for comparison with Figure 10).

learning arises from their educators adopting new, effective teaching strategies for designing learning experiences.

The conceptual difficulty is that the Learning Design framework tries to avoid privileging any particular pedagogical theory over another in its notational system, and yet almost all educators who could use Learning Design would wish to use it to improve learning, and improving learning requires a theory of how students learn.

We propose two ways to approach this problem. In the first approach, we have provided a Learning Design Conceptual Map to help explore the relationships among the "moving parts" of how an educator comes to teach in a particular way at a particular moment. The LD-CM provides a way for approaching this question that focuses on the core Learning Design concepts (guidance, representation and sharing) but also draws attention to the many related issues that affect the decision-making of educators.

Given a particular instance of teaching and learning, the LD-CM can be used to investigate how assumptions about theory and the learning environment relate to teaching plans, classroom activities and learner responses. In broad terms, it is a question of the internal coherence of actions within a given set of pedagogical (and other) assumptions. As everyday teaching is littered with examples that lack this kind of coherence, it is not an insignificant issue.
However, this first approach is, in part, a fudge. A thoroughgoing relativist interpretation might say that internal coherence is the only question that could be asked, as there is no "reality" by which to externally judge questions of teaching and learning effectiveness. However, the vast majority of educators believe there are more and less effective ways of teaching, arising from their observations of learner responses and the findings of educational research. In addition, most pedagogical theories ultimately contain ideas about how an educator "should" and "should not" go about teaching, which belies a view about reality (otherwise there would be no "should").

Our second approach starts by using the Learning Design Conceptual Map, where a chosen pedagogical approach can be described in the Educational Philosophy box. This choice is, ultimately, informed by evidence from the Theories and Methodologies box immediately below it, which deals with evidence from educational research. Different kinds of research evidence frequently provide support for different pedagogical theories - for example, quantitative analysis of small activities might be used to support particular types of direct instruction theories, whereas broad qualitative analyses of the skills of learners on reaching the end of their education might be used to support constructivist theories. 


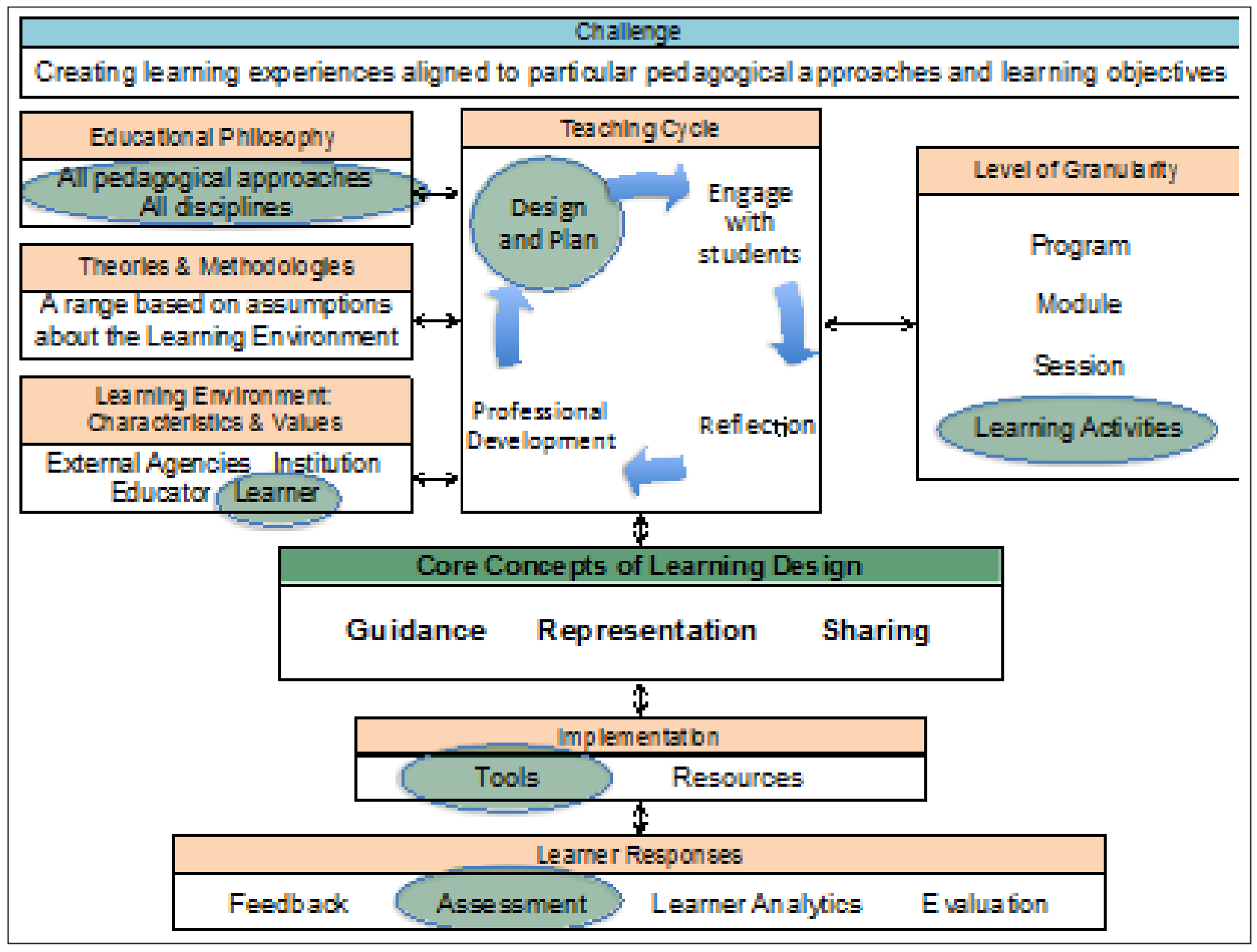

Figure 10: Example of LD-CM overlay for significant areas of interest for a SCORM single-learner courseware approach (for comparison with Figure 9).

This is not the place for a debate over the validity of different pedagogical theories and their underlying evidence. Rather, we seek to use the LD-CM to draw attention to the way that different kinds of research evidence inform different pedagogical theories that in turn inform different teaching and learning activities which can be represented using a Learning Design notational system. At the level of individual educators, the explication of these connections can help to clarify decision-making about teaching and how these decisions connect pedagogical theory, research evidence, learner characteristics and context in order to promote effective student learning. At a macro level, the same Map can be used to help structure academic debate about types of research evidence (including whether particular evidence is conflicting or rather about different facets of education), and the links between research evidence and types of teaching and types of student learning, in order to facilitate judgements about effective learning.

For everyday practice, the question of teaching and learning effectiveness depends not simply on the chosen pedagogical theory or the research evidence in favour of this theory. It depends on the wider mix of issues identified in the LD-CM such as: the characteristics and values of institutions, educators and learners; the nature of the teaching cycle (and the granularity of teaching design); the use of descriptive frameworks for teaching and learning activities, together with guidance and sharing; the use of tools and resources to support implementation of teaching and learning; and the various responses of learners (e.g., reactions, assessment, evaluation).

The "best" pedagogical theory may be highly ineffective for student learning in a particular context if other parts of the LD-CM are not considered or implemented appropriately. Equally, a set of very difficult educational circumstances (e.g., education in a poor country) may still lead to highly effective learning where certain elements (e.g., a gifted teacher) overcome difficulties. Any thorough investigation of the effectiveness of a teaching and learning approach needs to examine the full set of interactions within the Learning Design Conceptual Map, including the potential for positive aspects of one part of the Map to override negative aspects in another part.

\section{Part 5.1: Is effective teaching and learning always "learner-centred"?}

There is one final issue in pedagogical theory that is relevant to this discussion of Learning Design. Many educators, particularly in the past, have tended to teach using methods that focus heavily on content transmission, and less on active learning activities for learners (such as student-led analysis, research and discussion as used in Problem-Based Learning). A preference for content 
transmission approaches is rarely due to a sophisticated understanding of the evidence to support this approach, rather, it is often simply a replication of the experience of past teaching practices - that is, educators often teach the way they themselves were taught.

This issue takes several forms. One has been a desire to shift education from being "teacher centred" to "learner centred", or "teaching centred" to "learning centred", or from the "sage on the stage" to the "guide on the side". This general view seeks to focus attention primarily on how the learner learns (and hence how all other aspects of education should revolve around this) rather than simply how the teacher teaches. Another way to view this is a shift from an "input" model of education (what the educator imparts to learners) to an "output" model of education (what do learners know and can do following teaching and learning activities). A focus on what learners actually learn is essential to an understanding of effective teaching and learning, and so to the extent that "learner-centred" means "what works for student learning", then being "learner-centred" is the foundation of effective teaching and learning.

But learner-centred is sometimes taken to mean that all learning must be led by the learner, and that teaching, particularly any type of direct instruction or drill and practice-style teaching, should be avoided. Given the many examples of ineffective content transmissionstyle teaching, based on unreflective past experiences of teaching, it is understandable that in some contexts there is a reaction against "teacher-centric" methods. In some circles, "teaching" is almost a dirty word.

However, this reaction against teaching can go too far. Even in teaching contexts with a strong focus on the learner, there is usually an important role for the educator in structuring the opportunities for learning, and scaffolding the learning process to assist learners to learn. These structuring and facilitation decisions can still be described and shared using a Learning Design descriptive framework.

Going further, different teaching approaches may be used for different subjects, and at different stages in learning. Certain kinds of learning may benefit more from direct instruction approaches (e.g., language learning, basic mathematics), whereas other kinds of learning may benefit from collaborative or constructivism approaches (e.g., $21^{\text {st }}$ century skills). Hence, lecturing has a place among the suite of teaching methods that can assist a learner to learn. So, to the extent that "learner-centred" means little or no role for educators, we see many contexts in which this will not result in the most effective learning for students. Ill-informed and unguided discussion can be as ineffective for learning as poor content transmission.

This is not the place for a debate on the relative merits of different teaching and learning approaches for different subjects or stages of education, but we simply make the point that educators can use all the components of the Learning Design Conceptual Map to assist with designing and implementing effective teaching and learning activities, where the effectiveness is ultimately measured in terms of learning outcomes rather than teaching inputs. For most educators, this means using a wide range of teaching and learning approaches depending on what is most effective in their context. And to the extent that sharing learning designs helps educators to adopt new, effective teaching and learning methods, then ultimately student learning will improve.

\section{Conclusion: Revisiting Learning Design Definitions}

Many educators already use the phase "Learning Design" in a much more general sense than an abstract framework for describing teaching and learning activities or a Conceptual Map. Educators often use "Learning Design" to talk about their everyday decisions about how they teach, in the sense of "how do I design activities to help my learners to learn?" This is Learning Design as a practice - a verb rather than as a static concept - a noun to describe a field of study. It is Learning Design as "designing for learning".

At this point we are conscious of Peter Goodyear's caution that learning takes place inside the learner, and so there is nothing an educator can do to ensure that learning takes place (Goodyear \& Retalis, 2010). However, an educator can carefully design teaching and learning activities that encourage learning to take place - this is what we mean by "designing for learning".

Given the conceptual foundations we have laid in this paper and our discussion of effective teaching and learning approaches, we now offer a new synthesis for the field of Learning Design. The concept of a framework for describing teaching and learning activities (based on many different pedagogical approaches) that we have earlier defined as "Learning Design" can now be given a more precise phrasing as a "Learning Design Framework" (LD-F). The Learning Design Conceptual Map (LD-CM) provides the link between the core concept of the LD-F (together with guidance and sharing) and the wider educational landscape. The day-to-day practices of educators as they design for learning, and increasingly use the evolving Learning Design Frameworks and the Learning Design Conceptual Map to guide them, can be called Learning Design Practice (LD-P). Taken together, these three ideas provide a foundation for the future of the field of Learning Design - see Figure 11. A summary of the central ideas of the whole Larnaca Declaration on Learning Design is provided in the Appendix.

Given the breadth of this new definition of Learning Design, it is reasonable to ask whether the scope of Learning Design has become so broad as to be synonymous with "good pedagogy". While the rich pedagogical literature on effective teaching and learning is all relevant to Learning Design, a distinction can be drawn between the core Learning Design concepts of Representation, Guidance and Sharing - and how these are implemented primarily in the "design and plan" step in the Teaching Cycle - and the wider goal of good pedagogy. One example of where the line can be drawn is the skill of adapting in the moment while teaching - we believe this is an essential skill of educators, but it is not the same as Learning Design; and a training course for educators that taught both Learning Design and adaptation would be teaching quite different types of skills. Future research can be 


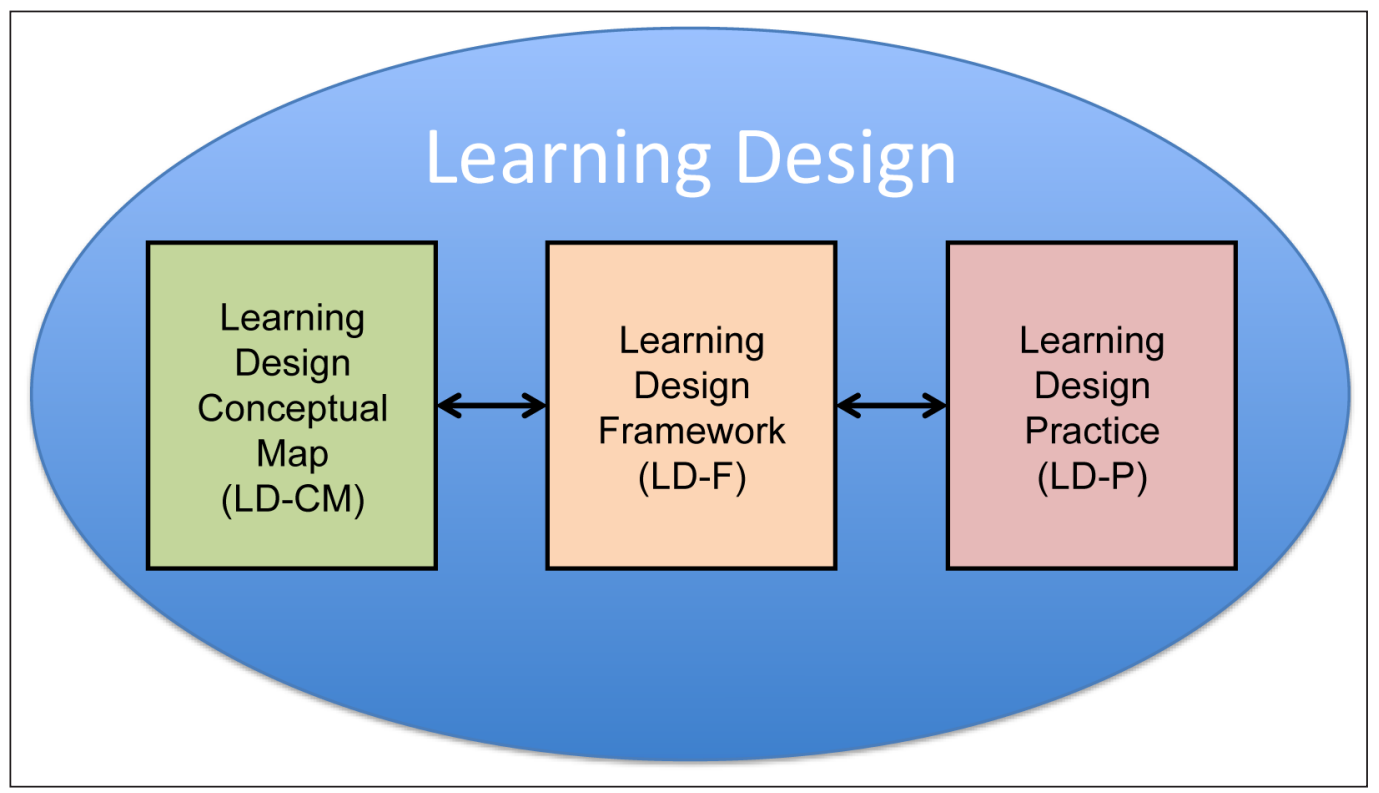

Figure 11: Components of the field of Learning Design.

expected to further delimit the core of Learning Design (LD-F and LD-P), the factors that affect it (LD-CM), and the wider context of all relevant skills and understanding for effective teaching.

\section{Epilogue}

The development of music notation was crucial to the widespread propagation of beautiful music. While education is yet to develop a comparable system of notation, research on Learning Design Frameworks gives us hints of what this might look like in the future, informed by the wider Learning Design Conceptual Map. If a notation system (or systems) for describing teaching and learning activities is developed and widely adopted, its success will be due to a complex mixture of its accuracy, expressiveness and historical contingencies. Its ultimate goal, though, is not just representation for representation's sake, it is to help educators to describe, share and adapt effective teaching and learning activities - that is, designing for learning, or Learning Design Practice.

It may be that the analogy of music notation will take us a considerable distance, but later be found to be missing some elements of education. The need for educators to adapt or "improvise" in the act of teaching in response to their interactions with learners seems one significant issue for deeper consideration. Perhaps Jazz music will provides an enriched music analogy - it is an example of music that can be retrospectively notated like other music, and yet the act of performance is often based on a combination of professional skill together with just the essence of some musical idea (as opposed to performance of a complete, static musical score).

In this paper we have used the success of Western music notation to help us imagine a similar system of educational notation. In practice, we already have a range of proto-notational examples, and it may be that several different education notation systems will arise in the future, each with different descriptive strengths and weaknesses.
Within any given system, there may be multiple diagrams needed to convey the richness of teaching and learning activities (like the multiple diagrams of UML in software development). So while the analogy of music notation can take us far, we believe a unique solution for education will be needed that is unlike anything else. The challenge, now, is to create it.

If education fails to develop a general system of notation, it is hoped that even the attempt to do so will teach us deep truths about the fundamental nature of education, and that these truths themselves will contribute to more effective teaching and learning approaches in the future.

\section{Competing Interests}

JD is a Director and owner of LAMS International Pty Ltd and the LAMS Foundation Ltd. All other authors have no competing interests..

\section{Appendix}

Summary of Larnaca Declaration on Learning Design

The central ideas about Learning Design in the Larnaca Declaration can be summarised as:

- Representing learning designs in formal ways (LD-F)

- Sharing and re-using learning designs

- Encouraging localisation of learning designs for the needs of learners, and adaptation to different disciplines

- Focusing on pedagogy in all its forms across all sectors and disciplines (LD-CM)

- Applying the teaching cycle to implementing and improving learning designs

- Emphasising how learners learn, and hence how educators can teach effectively (LD-P)

- Building software to implement and share learning designs

\section{Glossary}

Learning Design (capitalised): The field of Learning Design 
a learning design (uncapitalised): An individual example of a sequence of teaching and learning activities, also called a "design" or "sequence". A learning design is a plan for potential activities with learners, which is to be distinguished from a particular implementation of this plan with a particular group of learners (see "a running learning design")

a running learning design: The implementation of a learning design with a particular group of learners, also called "a running sequence".

IMS Learning Design: An example of a technical language for implementing the concepts of Learning Design in software

Learning Design Conceptual Map (LD-CM): A map of the wider educational landscape as it relates to core Learning Design concepts - see Figure 4

Learning Design Framework (LD-F): A descriptive language/notational format/visualisation for describing teaching and learning activities based on many different pedagogical approaches

Learning Design Practice (LD-P): The action of applying Learning Design concepts to the creation and implementation of effective teaching and learning activities, also called "designing for learning"

teaching strategy: An approach to teaching that proposes a particular sequence of teaching and learning activities based on certain pedagogical assumptions. Examples of teaching strategies are capitalised in this paper, for example, Problem Based Learning, Predict - Observe Explain, Role Plays and WebQuests. A teaching strategy can provide a pedagogical rationale as well as a suggested structure of activities for a learning design.

\section{Acknowledgements}

Support for this publication has been provided by the Australian Government Office for Learning and Teaching. The views expressed in this publication do not necessarily reflect the views of the Australian Government Office for Learning and Teaching.

This paper was based on ideas arising from a meeting of Learning Design experts in Larnaca, Cyprus on Tuesday $25^{\text {th }}$ September 2012 and subsequent discussions (hence the name "Larnaca Declaration on Learning Design").

Before and after the Larnaca meeting, a number of other meetings have discussed similar issues, and these discussions have contributed to the current ideas. Participants in these other meetings have included: Diana Laurillard, Spyros Papadakis, Chris Alexander, Liz Masterman, Sheila MacNeill, Scott Wilson, Yannis Dimitriadis, Peter Goodyear, John Hedberg, Gregor Kennedy, Paul Gagnon, Debbie Evans, Kumiko Aoki, Carlos Alario, Chris Campbell, Matthew Kearney, Ron Oliver, Shirley Agostinho, Lori Lockyer and others. We are grateful to all our colleagues for their insights.

\section{Notes}

${ }^{1}$ We have chosen "educator" rather than "teacher" to provide a more inclusive term that applies not only to $\mathrm{K}-12$ teachers, but also to university lecturers and vocational/professional trainers.
${ }^{2}$ We mean classrooms in the broadest sense - also including lecture halls, seminar/tutorial rooms, laboratories, fieldwork contexts and online.

${ }^{3}$ Educators can play many different roles in the overall education lifecycle, such as: preparing educational content, preparing teaching and learning activities, implementing activities with learners in classrooms and online, facilitating discussion among learners, conducting and marking assessment, using evaluation to improve future education and others. In some cases, a single educator plays all of these roles for a group of learners; in others, a different educator may play each role. In this paper we use educator to mean anyone who plays any of these roles, and hence could benefit from examples of good practices and advice on adopting these practices.

${ }^{4}$ Learning Management Systems (LMSs) are sometimes called Virtual Learning Environments (VLEs)

\section{References}

AUTC Learning Design 2002 Predict - Observe - Explain: Designer's Voice - Context. Available at: http://www. learningdesigns.uow.edu.au/exemplars/info/LD44/ more/03Context.html.

Bower, M, Craft, B, Laurillard, D and Masterman, L 2011 Using the Learning Designer to develop a conceptual framework for linking learning design tools and system. In Cameron, L and Dalziel, J (Eds.) Proceedings of the 6th International LAMS \& Learning Design Conference 2011: Learning design for a changing world. 8-9 December 2011. Sydney: LAMS Foundation, pp 61-71. Available at: http://lams2011sydney.lamsfoundation. org/docs/RP/Bower_Matt.pdf.

Britain, S 2004 A Review of Learning Design: Concept, Specifications and Tools. A report for the JISC E-learning Pedagogy Programme. Available at: http://www. jisc.ac.uk/uploaded_documents/ACF1ABB.doc.

Conole, G 2012 OULDI Course Map. Available at: http:// jiscdesignstudio.pbworks.com/w/page/33031185/ OULDI\%20-\%20Course\%20Map.

Conole, G 2013 Designing for Learning in an Open World. New York: Springer. DOI: http://dx.doi. org/10.1007/978-1-4419-8517-0

Dalziel, J 2003 Implementing Learning Design: The Learning Activity Management System (LAMS). In: Crisp, G, Thiele, D, Scholten, I, Barker, S and Baron, J (Eds.) Interact, Integrate, Impact: Proceedings of the 20th Annual Conference of the Australasian Society for Computers in Learning in Tertiary Education. Adelaide, 7-10 December 2003. Available at: http://ascilite.org. au/conferences/adelaide03/docs/pdf/593.pdf.

Derntl, M, Parrish, P and Botturi, L 2010 Beauty and Precision: Weaving Complex Educational Technology Projects with Visual Instructional Design Languages. International Journal on E-Learning, 9: 185-202

Dimitriadis, Y 2012 Collaborative learning flow patterns. Available at: http://www.gsic.uva.es/wikis/yannis/ images/c/cc/Collaborative_learning_flow_patterns. pdf. 
Goodyear, P and Retalis, S 2010 Technology-enhanced learning: design patterns and pattern languages. Rotterdam: Sense Publishers.

Hernández-Leo, D, Villasclaras-Fernández, E D, Asensio-Perez, J I, Dimitriadis, Y, Jarrín-Abellán, I M, Ruiz-Requies, I and Rubia-Avi, B 2006 COLLAGE: A collaborative Learning Design editor based on patterns. Educational Technology and Society, 9: 58-71.

Hooker, K W 1949 College Teaching: The Loneliest Profession. Bulletin of the American Association of University Professors (1915-1955), 35: 643-650.

IMS GLC 2003 Learning Design specification. Available at: http://www.imsglobal.org/learningdesign/.

Koehler, M and Mishra, P 2009 What is Technological Pedagogical Content Knowledge (TPACK)? Contemporary Issues in Technology and Teacher Education, 9: 60-70.

Koper, E J R 2001 Modelling Units of Study from a Pedagogical Perspective: The pedagogical metamodel behind EML. Heerlen: Open Universiteit Nederland. Available at: http://eml. ou.nl/introduction/docs/ped-metamodel.pdf.

Laurillard, D 2002 Rethinking University Teaching: A Conversational Framework for the Effective Use of Learning Technologies. ( $2^{\text {nd }}$ Edn) London: RoutledgeFalmer. DOI: http://dx.doi.org/10.4324/9780203304846
Laurillard, D and McAndrew, P 2002 Virtual Teaching Tools: Bringing academics closer to the design of e-learning. Available at: http://kn.open.ac.uk/public/getfile. $\mathrm{cfm}$ ?documentfileid $=7517$.

Littlejohn, A and Pegler, C 2007 Preparing for Blended E-Learning. London: Routledge.

Masterman, E and Manton, M 2011 Teachers' perspectives on digital tools for pedagogic planning and design. Technology, Pedagogy and Education, 20: 227-246. DOI: http://dx.doi.org/10.1080/1475939X.2011.588414

McAndrew, P, Goodyear, P and Dalziel, J 2006 Patterns, designs and activities: Unifying descriptions of learning structures. International Journal of Learning Technology, 2: 216-242. DOI: http://dx.doi.org/10.1504/ IJLT.2006.010632

Prieto-Santos, L P, Dimitriadis, Y, Villagrá-Sobrino, S L 2011 Representing learning design and classroom orchestration through atomic patterns Proceedings of the Art and Science of Learning Design international workshop, ASLD 2011, London, UK, October 2011. Available at: http:// www.gsic.uva.es/uploaded_files/36400_20110811_ UVa_RepresentingClassroomPractice.pdf.

Walker, S and Kerrigan-Holt, M 2012 Map My Programme. Available at: http://www.mapmyprogramme.com/.

\footnotetext{
How to cite this article: Dalziel, J, Conole, G, Wills, S, Walker, S, Bennett, S, Dobozy, E, Cameron, L, Badilescu-Buga, E and Bower, M 2016 The Larnaca Declaration on Learning Design. Journal of Interactive Media in Education, 2016(1): 7, pp. 1-24, DOl: http://dx.doi.org/10.5334/jime.407

Submitted: 30 October 2015 Accepted: 04 December 2015 Published: 10 February 2016

Copyright: (c) 2016 The Author(s). This is an open-access article distributed under the terms of the Creative Commons Attribution 4.0 International License (CC-BY 4.0), which permits unrestricted use, distribution, and reproduction in any medium,
} provided the original author and source are credited. See http://creativecommons.org/licenses/by/4.0/.

] $\mathbf{u}$ Journal of Interactive Media in Education is a peer-reviewed open access journal published by Ubiquity Press. 